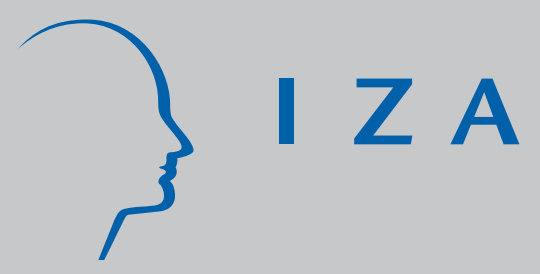

IZADP No. 3438

How Viable Are Unemployment Insurance Savings Accounts: Simulation Results for Slovenia

Milan Vodopivec

April 2008 


\title{
How Viable Are Unemployment Insurance Savings Accounts: Simulation Results for Slovenia
}

\author{
Milan Vodopivec \\ World Bank and IZA
}

\author{
Discussion Paper No. 3438 \\ April 2008
}

IZA

P.O. Box 7240

53072 Bonn

Germany

\author{
Phone: +49-228-3894-0 \\ Fax: +49-228-3894-180 \\ E-mail: iza@iza.org
}

\begin{abstract}
Any opinions expressed here are those of the author(s) and not those of IZA. Research published in this series may include views on policy, but the institute itself takes no institutional policy positions.

The Institute for the Study of Labor (IZA) in Bonn is a local and virtual international research center and a place of communication between science, politics and business. IZA is an independent nonprofit organization supported by Deutsche Post World Net. The center is associated with the University of Bonn and offers a stimulating research environment through its international network, workshops and conferences, data service, project support, research visits and doctoral program. IZA engages in (i) original and internationally competitive research in all fields of labor economics, (ii) development of policy concepts, and (iii) dissemination of research results and concepts to the interested public.
\end{abstract}

IZA Discussion Papers often represent preliminary work and are circulated to encourage discussion. Citation of such a paper should account for its provisional character. A revised version may be available directly from the author. 


\section{ABSTRACT \\ How Viable Are Unemployment Insurance Savings Accounts: Simulation Results for Slovenia*}

By simulating the working of the unemployment insurance savings accounts (UISAs) in Slovenia using a methodology similar to Feldstein and Altman (1998), the paper examines two questions: how viable is this system as an alternative to traditional unemployment insurance (UI) system, and how the redistribution of income changes if the UI system is replaced by UISAs. The simulations are performed on a representative sample of labor force participants, for which lifetime labor market histories are generated from administrative panel data. Simulations show that the UISA system is a viable alternative to a modest UI system, but that its viability is jeopardized under generous benefits. Under the modest regime (here identified with a post-1998 period, the period after the UI reform which strongly reduced the maximum potential duration of benefit, for most workers even by half) our calculations show that only one quarter of workers end their working life with negative cumulative balance and 43 percent ever experience a negative UISA balance; in contrast, under the generous regime (here identified with the pre-1998-reform period), 49 percent of workers end their working life with negative cumulative balance and 66 percent ever experience a negative balance. Moreover, under the modest benefit regime workers are better able to recover positive UISA balance. The simulations also show that the level of redistribution under the UISAs lags substantially behind the UI system, even though the version of the UISAs studied permits borrowing and hence allows for redistribution.

JEL Classification: J65, C23

Keywords: unemployment insurance, unemployment insurance savings accounts

Corresponding author:

Milan Vodopivec

The World Bank

1818 H Street, NW

Washington, D.C. 20433

USA

Email: Mvodopivec@worldbank.org

\footnotetext{
${ }^{*}$ The author is grateful to the Statistical Office of Slovenia and to the National Employment Office of Slovenia for providing data and to Tomaž Rejec for excellent research assistance.
} 


\section{Table of contents}

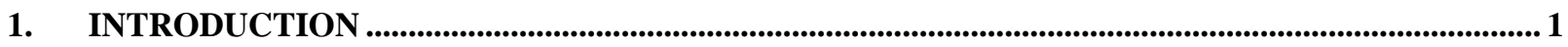

2. UNEMPLOYMENT INSURANCE SAVINGS ACCOUNTS: WHAT DO WE KNOW ABOUT

THEM? ............................................................................................................................................................

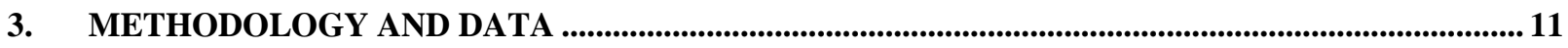

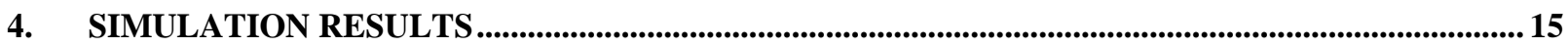

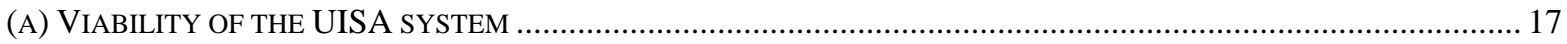

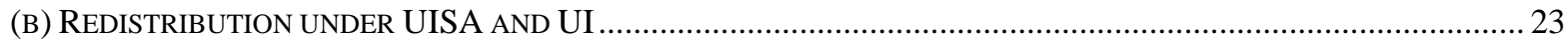

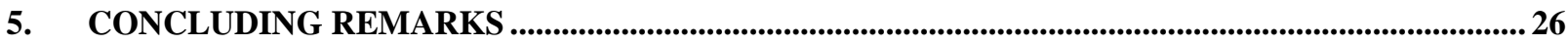

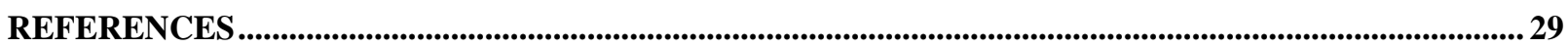

APPENDIX 1: OBTAINING COMPLETE WORK HISTORIES FOR SIMULATION COHORTS........................ 40

APPENDIX 2: CALCULATION OF SIMULATED VARIABLES ................................................................................. 46 


\section{Introduction}

While the traditional system of unemployment insurance (UI) provides protection against the hardship of job loss, there is growing persuasion and new evidence that, in the words of Meyer (1995), “unemployment insurance is not a completely benign transfer; it affects claimant’s behavior” (p. 127). Indeed, evidence shows that UI - even under the best program design and strict monitoring - creates adverse incentives which reduce job-search efforts and increase overall unemployment (see Vodopivec 2004 for an extensive evaluation of both income protection as well as efficiency aspects of UI and other income support programs for the unemployed).

Spurred by adverse incentives created by traditional income support systems, new approaches to improve these systems have been embarked upon. The system of UI savings accounts (UISAs) is among the most radical and perhaps also promising ones. Under the UISA system, each worker is required to save a fraction of earnings in his or her account, and draw unemployment compensation from it. By internalizing the costs of unemployment benefits, the UISA system is expected to radically change workers' incentives and thus to avoid the moral hazard inherent in traditional UI schemes - while, under some proposals, providing same protection to the unemployed as the traditional UI system does. Too little, however, is known about the working of the UISA system to know for which groups of workers, and under what conditions, this favorable assessment of the system actually holds true.

This paper is an attempt to provide insights into the working of the UISA system by simulating its introduction in one of transition economies - Slovenia. In particular, it addresses the following two questions: 
- How viable is the UISA system? UISAs eliminate pooling across individuals. If a significant proportion of workers cannot generate sufficient savings to draw upon during their unemployment spells, such a system may be non-viable.

- What redistributive effects are produced by the replacement of the UI system with the UISA system? According to Feldstein and Altman (1998), such redistributive effects for the U.S. are likely to be small - what can be expected for transition countries?

For both substantive as well as data reasons, Slovenia is a very attractive case for a UISAs simulation study. On substantive grounds, there are two main reasons. First, Slovenia has a comprehensive, well-developed system of UI. In the 1990s, the system offered relatively generous unemployment benefits to about one third of the unemployed (for a review of unemployment benefit systems of European transition countries in the 1990s which summarizes both efficiency and income protection impacts, see Vodopivec et al, 2005). ${ }^{1}$ Second, the 1998 drastic reform of the Slovenian UI system that reduced the potential duration of unemployment benefits offers a possibility to study the introduction of UISA under two types of regimes of benefit generosity: a generous and a modest regime. The UI reform strongly reduced the maximum potential duration of benefit, for most workers even by half, allowing us to study the effects of UISAs introduction under both the generous, pre-1998 benefit regime, as well as under the modest, post-1998 benefit regime. And there are clear advantages of Slovenia's administrative databases: they offer exceptionally rich information (panel microdata covering labor market histories of all formal labor force participants covering pre- and post-1998 UI

\footnotetext{
${ }^{1}$ Similar to OECD countries, Slovenia provides income support to the unemployed via a social insurance program consisting of a combination of UI and unemployment assistance (UA). The program covers the majority of employed persons, irrespective of industry or occupation (the most notable exception are the self-employed). Under employment insurance, the benefits have been earnings related and the duration of entitlement is contingent on the length of work experience, with predetermined maximum and minimum levels. Benefits under UA are means-tested
} 
reform period), thus allowing the application of the Feldstein-Altman simulation methodology which relies on long panel coverage of a representative sample of workforce participants.

Our simulations show that the UISA system is a viable alternative to a modest UI system, but that its viability is jeopardized under generous benefits. Under the modest regime (here identified with a post-1998 period) our calculations show that only one quarter of workers end their working life with negative cumulative balance and 43 percent ever experience a negative UISA balance; in contrast, under the generous regime (here identified with the pre-1998 period), 49 percent of workers end their working life with negative cumulative balance and 66 percent ever experience a negative balance. Moreover, under the modest benefit regime workers are better able to recover positive UISA balance. The simulations also show that the level of redistribution under the UISAs lags substantially behind the UI system, even though the version of the UISAs studied permits borrowing and hence allows for redistribution.

The paper is organized as follows. To familiarize the reader with this rather new and not well-known system, section 2 presents the UISA system: it describes its functioning, points out the potential viability problem that the UISA system may suffer from, and discusses redistributive effects of replacing the traditional UI system by the UISA system. Section 3 describes the methodology and data sources, and section 4 presents the simulation results. Section 5 summarizes the results and derives policy implications.

and offered to those who exhausted their eligibility to UI, and selected groups of other workers who do not qualify to UI benefits. 


\section{Unemployment Insurance Savings Accounts: What Do We Know About Them?}

Partly in response to the shortcomings of the traditional UI, the idea of UISAs has gained popularity in recent years. The main rationale and the key appeal of the UISA system as an alternative to the traditional UI system is its potential of improving the incentives of employed workers and job-seekers while simultaneously providing the same protection as traditional insurance schemes.

UISAs, however, is still very much a novel idea and thus it is premature to give a reliable evaluation of this system as an alternative to traditional unemployment support schemes. Much less empirical evidence exists about this system than about other systems of income support, and there has been no rigorous analysis of existing UISA systems. Nonetheless, this idea has attracted a lot of attention in Latin America, where variants of this system have recently been introduced by Argentina, Chile, Colombia, Ecuador, Peru, and Uruguay. In Brazil, such a variant has been in place for several decades. Below we describe a stylized system of UISAs and review the theoretical and empirical literature on the effects of such a system.

Description. The UISA system functions as follows. Employers deposit for each worker some specified fraction of his or her earnings into a special individual savings account on a regular basis. ${ }^{2}$ In some countries (Chile), workers are also required to make regular contributions into their accounts. Upon separation and regardless of the reason for separation, workers can

\footnotetext{
${ }^{2}$ In Brazil, Ecuador, Columbia, there is $8 \%$ contribution rate, and in Peru, one half of a monthly salary each six months; contributions are paid by employers in workers' individual savings accounts. In Uruguay employees contribute 15 percent of earnings: the first 7.47 new pesos goes to social insurance and the balance, less a 3 percent administrative fee, goes to an individual account. Employers contribute a further 12.5 percent of payroll to the system and the government, if necessary, finances deficits (this is a dual social/ private insurance system which covers old age, disability, death, sickness and maternity benefits, family allowances and unemployment) (Lipsett (1999), Heckman and Pages (2000), Mazza (2000).
} 
make withdrawals from their savings accounts as they deem fit. However, in Brazil, workers can only access their accounts upon involuntary separation, and in such cases, employers are required to make an additional payment of 40 percent of the account balance (plus interest) to the individual as penalty. In Panama and Venezuela, the penalty for involuntary withdrawals is set as a multiple of previous wages, and offered regardless of the reason for separation. In Chile, workers can only access the solidarity fund in the case of involuntary separation. In all countries, at retirement, positive account balances are added to old-age pensions. Some programs allow workers to access their savings accounts for reasons other than unemployment, such health and education.

According to some proposals (see, for example, Cortazar, 1996, and Feldstein and Altman, 1998), unemployed workers would be able draw benefits monthly as under the traditional UI, and the government would lend money to accounts where the balance falls below zero. A close variant of this arrangement was recently introduced in Chile in 2002. In the Chilean system, employers and workers make contributions into individual savings accounts. At the same time, workers and the government make contributions into a separate fund called the "Solidarity Fund.” When drawing unemployment benefits and under certain conditions, if the account balance of the beneficiary falls below a stipulated minimum, the difference is made up via transfers from the Solidarity Fund.

To improve both the welfare and efficiency effects, the UISAs could be combined to provide protection against other risks as well. ${ }^{3}$ Such recent proposals include the "Integrated Unemployment Insurance System” (Yun, 2001). Under this system, UI is provided via

\footnotetext{
${ }^{3}$ Such is the current dual social/private arrangement in Uruguay, where the individual savings account covers not only unemployment benefits, but also old-age pension, disability, death, sickness and maternity benefits, as well as family allowances (Lipsett, 1999).
} 
integrating UI with the pension system. Benefits are financed via a combination of withdrawals from an individual savings account - on which a worker accumulates his/her contributions for unemployment as well as for old-age pensions - and, under certain circumstances, also from a public UI (which operates on a pay-as-you-go basis). Such a program thus combines intertemporal pooling of risk of an individual with wide-base pooling under the traditional UI system, and therefore offers a combination of self-insurance through savings and public insurance. In addition, it combines several risks under one program, thus pooling the self-insurance component and reducing the amount of savings necessary for providing the same insurance under separate programs (indeed, there are also proposals to include other social insurance systems, such as disability and health-care, under the same roof, which - under certain conditions - is again welfare improving - see Orszag et al, 1999).

As Orszag and Snower (1997) point out, such a system could either be fully funded or financed on the pay-as-you-go (PAYG) basis. The main rationale for the PAYG approach, according to the authors, is the reluctance of most OECD countries to quickly embark on the transition to a funded system. In developing countries, another argument in favor of the PAYG approach are insufficiently developed financial markets. However, by opening a host of familiar problems plaguing PAYG pension systems (among others, re-introduction of intra- as well as inter-generational transfers, lack of transferability, susceptibility to political risk, avoidance of raising the national savings), this option needs to be carefully examined.

Incentives under unemployment insurance saving accounts. According to theoretical modeling, the main rationale and key advantage of the UISA system as an alternative to the traditional UI system is its potential of improving the incentives of employed workers and job seekers while conceivably providing the same protection as traditional UI. As shown by several 
theoretical papers, UISAs would radically change workers' incentives (Orszag and Snower, 1997; Orszag et al, 1999). By internalizing the costs of unemployment benefits, the UISA system avoids the moral hazard inherent in traditional UI. The system is thus credited with a potential to substantially decrease overall unemployment and, by lowering payroll taxes, increase wages. In particular, Orszag and Snower (1997) show that UISAs reduce unemployment by both increasing on-the-job effort of employed workers as well as job-search effort of unemployed workers. ${ }^{4}$ Orszag et al (1999) also recommend a comprehensive vs. a piecemeal approach when introducing savings accounts. They warn that a potential complementarity problem exists if the savings account is not set up for multiple uses: under the traditional unemployment system, workers who have built up substantial resources in their pension accounts have the incentive to withdraw from the labor force and claim unemployment benefits until they retire. Setting up an integrated savings account reduces such incentives.

There are also other advantages of the "Integrated Unemployment Insurance System." By combining several risks under one program, the system is expected to offer not only superior provision of insurance and thus consumption smoothing, but also to significantly reduce disincentives as compared to the traditional UI system. In addition, the government could subsidize low wage workers, which would improve the distributive properties of the system. Moreover, because of the direct link between contributions and benefits, the system has the potential to attract informal sector workers. While details of the system still need to be determined, theoretical modeling suggests that the more risk averse is the individual and the lower is the job-search elasticity (that is, the less sensitive is the reemployment probability to job

\footnotetext{
${ }^{4}$ But note that some workers may stay unemployed so as to be able to draw benefits from their UISA accounts rather than exit to inactivity, and thus there are also some factors which might contribute to higher unemployment under the UISA system.
} 
search), the higher is the level of optimal borrowing from the public part of the system (Yun, 2001).

Empirical evidence. UISAs are still largely an "uncharted territory." Much less empirical evidence exists about this system than about other systems of income support, and apart from Kugler’s (2000) evaluation of the Colombian program - there has been no rigorous analysis of existing UISA programs. In her pioneering study, Kugler (2000) examines the effects of a 1990 conversion of the severance pay program into an UISAs program in Colombia. She finds that the lion's share of the costs of the transfer that firms make to individual workers' accounts (75-87 percent) show up as a reduction of wages; that implies that the likely effects of the new program on the reduction of labor demand and employment are small. She also finds that, in accordance with the theoretical predictions, the conversion increased both firing and hiring by firms, in comparison with the previous system of severance pay. Her work, however, does not shed light on the interesting question of the effects of UISAs on the reemployment probability, that is, whether or not the system improves job search incentives.

There has been no other rigorous empirical work about the effects of real world UISAlike systems. Some researchers, however, have reported that the Brazilian FGTS system, while avoiding the problem of disincentives in job search found under UI, creates incentive and other problems of its own (Gill et al, 2000). First, the system creates perverse incentives on the part of the worker to precipitate a firing so as to be able to access the funds in the savings account. It is estimated that the system increases the labor turnover rates by 30 percent. Second, it also creates additional litigation costs incurred in deciding whether or not the cause for dismissal is "just." More research as well as piloting is needed to learn whether problems of the Brazilian program can be avoided. 
The above discussion on the incentives under the UISA system is not complete, however. The elimination of the problem of adverse incentives applies only for individuals who save enough to maintain positive balances and who expect that they will end their working life with a positive balance. In contrast, workers who expect to end their working life with negative balances face the same incentives as under the traditional unemployment system. This consideration - which obviously has important consequences for the viability of the UISA system - is considered next.

Viability of UISAs. UISAs eliminate pooling of resources across individuals and, instead, rely on incomparably more restrictive intertemporal pooling of resources of one individual only. This raises an important viability question: if a significant proportion of workers cannot save enough - via modest contributions from their earnings -- during their productive life to draw upon their accumulated savings during their unemployment spells, then such a system is nonviable. In other words, if unemployment is concentrated among a group of workers, these workers may not be able to finance their unemployment benefits by their own savings. In contrast, there may be a large group of workers who would never use their savings account for unemployment purpose. Under such circumstances, the UISA system would be irrelevant as an alternative to the traditional UI system.

To investigate the viability of the system, Feldstein and Altman (1998) simulated the working of the UISA system for the U.S. In their simulations, the level and duration of benefits provided by the UISA system are completely the same as under the current UI system. Naturally, they assume that the UISA benefits are financed by the individual's UISA, to which individuals contribute 4 percent of their wages. Their simulations show that (i) over a 25 year period, only a small proportion of workers (5-7 percent) end their working life with negative balances (these 
estimates are conservative in the sense that they do not account for any behavioral responses to changes in incentives), and (ii) the cost to taxpayers is reduced by more than 60 percent. Feldstein and Altman thus conclude that the UISA system is a viable alternative to the standard UI system. Of course, their conclusion is valid for the U.S. economy. Since in other countries the probabilities of entry into and exit from unemployment differ substantially from those of the U.S., the conclusion of the viability of the UISA system cannot be extrapolated to other countries, particularly not to developing ones.

Distributive issues and UISAs. Arguably, the UISA system can in principle provide the same income protection as the traditional UI system does (with less adverse incentives, as discussed above). Switching to the UISA system, however, does have distributional consequences, because the benefits are financed in a different way. According to Feldstein and Altman (1998), however, the distributional effects for the U.S. are likely to be small - albeit they work in the "wrong" direction, that is, they tend to hurt the poor. Feldstein and Altman find that individuals in all quintiles except the bottom one slightly gain, and individuals in the bottom quintile slightly lose (distributive effects appear worse, because the simulation does not take account of behavioral responses to the changed incentives following the introduction of the UISA system). It is hard to predict what distributional effects the switch to UISA will have in the context of developing countries.

To summarize, the UISA system and its variant Integrated Unemployment Insurance System appear to be promising options, particularly for countries where initial conditions are especially suitable (for example, for countries where the existence of severance pay programs may ease the transition to an UISA system). By internalizing the costs of unemployment benefits, the program avoids the moral hazard inherent in the traditional UI program and thus 
improves reemployment incentives - given the weak monitoring capacity, an important advantage particularly for developing and transition countries. In its integrated version with public insurance, thus avoiding its main weakness - the absence of risk-pooling among individuals, the program promises to yield both superior protection and improved incentives, and has also the potential to attract informal sector workers. There is a need, however, for further investigation and piloting of the program. Little is known about the working of the UISA system to know for which groups of workers, and under what conditions, the above favorable evaluation of the system actually holds true (and important design parameters of the system regarding contribution rates and rules for withdrawal, for example, also need to be examined). By examining the consequences of the absence of cross-pooling for the viability and the distributive properties of the system, the current paper seeks to help bridging this gap.

\section{Methodology and Data}

We have adapted and extended the simulation methodology of Feldstein and Altman (1998), as dictated by data availability. The simulation consists of applying UISA rules to labor force participants over their entire working life, thus determining the histories of contributions to and withdrawals from individual worker UISA. This procedure is then used to derive characteristics of the UISA system which are suggestive of the viability and desirability of the system. The following characteristics are focused upon: the fraction of workers which end their active lives with negative cumulative balances on their UISAs; the fraction of workers who ever have had negative balances; and the share of public financing needed to finance unemployment benefits. Moreover, to gauge the distributional effects of the replacement of UI with the UISA system, we compare subsidizes given to, or taxes imposed upon, workers ranked by their lifetime wages 
under the two systems. We also perform an extensive test of robustness of the derived estimates with the respect of different parameter values of the UISA system.

It has to be emphasized that in our calculations, we ignore behavioral consequences which the new system is likely to bring. We refrained from such an exercise because in the absence of any data on the behavioral changes provoked by the changes of UI parameters, assumptions about the likely magnitude of such changes would be too speculative.

Below we present the simulation algorithm, explain how we distinguish between the generous and modest benefit regimes, and describe the construction of life-time work histories for individuals selected in simulation cohorts and data sources.

The simulation algorithm. We assume that each worker's UISA is empty at the time of entering the labor force. Thereafter, each worker contributes to his/her account during employment spells, and draws unemployment benefits during unemployment spells. Each month, the worker puts a fraction of his wage to his account, as set by the contribution rate. The contributions are waived when the balance on the account is above a predetermined maximum accumulation amount. Monthly withdrawals from the account are made when the worker is unemployed. The duration of the benefit receipt is limited by the maximum duration of benefits, and the level of the benefit is determined by the replacement rate (a given percentage of the person's previous wage). Benefit eligibility is further restricted according to minimum prior employment requirement.

In addition, we allow the UISA system to have an initial grace period during which the individual's benefit is not financed by withdrawals from the worker's UISA, but instead by the government. Moreover and most importantly, if the account sinks "in the red" (that is, if its balance is negative), the benefit is nonetheless paid to the worker and the negative balance of his 
account is further increased. To finance accounts with negative balances, the government taxes the employed workers in a similar way as under the standard UI system (note that we are referring to the contribution rate when resources are put into UISAs, and to the taxation rate when resources are used to finance benefits of workers with negative UISA balances). All UISA accounts also accrue (negative or positive) monthly interest payments, depending on their balances.

Distinction between the generous and modest benefit regimes. As mentioned, the 1998 reform of the Slovenian UI system that strongly reduced the potential duration of unemployment benefits allows us to study the introduction of UISA under both generous and a modest benefit regime. In particular, we associate the 1995-1998 labor market outcomes of UI benefit recipients as those pertaining to a "generous benefit regime," and the 2000-2001 outcomes as those pertaining to a "modest benefit regime."

The justification for the above distinction is as follows. Faced by an increasing trend in the number of unemployed, including UI recipients and long-term unemployed, Slovenia in October 1998 reformed its unemployment benefit system. The reform strongly shortened the length of the UI entitlement period, roughly by half for most groups of recipients, while leaving the replacement rate unchanged. For workers with 1.5-5 years of work experience, the reduction of entitlement period was from 6 to 3 months; for those with 5-10 years of experience, from 9 to 6 months; for those with 10-15 years of experience, from 12 to 6 months; for those with 15-20 years of experience, from 18 to 9 months; for those with 20-25 years of experience, from 24 to 9 months; and for workers with over 25 years of experience, from 24 to 12 and 18 months, respectively (depending on their age); only for workers with less than 1.5 years of experience and those older than 55 years the UI entitlement stayed unchanged. While before 1998 reform 
the Slovenian UI system was the most generous among the transition countries, the reform 1998 reduced its generosity to a level comparable to the one in other transition countries (see the analysis of generosity of UI benefit system by Vodopivec et al, 2005).

Construction of life-time work histories for simulation cohorts. In line with above distinction of the two benefit regimes, we formed two simulation cohorts consisting of 1000 randomly selected individuals, one pertaining to the generous and another to the modest regime. An obvious problem we had to overcome was the construction of a complete life-time work history for individuals selected in our simulation cohorts, as the simulation algorithm rests on such information and this information was not available from our data sources. To construct a complete life-time work history, we started with the observed work history of the selected individuals and extrapolated it by work histories of workers who matched certain selection criteria. Such a sequential merging, spanning over a complete work life, produced a complete work history for each of the workers selected in the simulation cohort (see Appendix 1 for details on the procedure).

Data sources. The simulations of the UISA system rest on unusually rich administrative data bases covering all Slovenian workforce participants in the period from 1992 to 2001: the work history, unemployment, and earnings data bases. Common personal identification numbers allow combining records from different data bases.

(a) Work history data base (maintained by the Statistical Office of Slovenia) was established by the census of workers in 1987 and initially included information on all formal sector jobs that were in progress as of December 31, 1986. Information collected about the individuals incumbent in these jobs included age, educational attainment, gender, years of labor market experience counted towards eligibility for the state-sponsored pension plan, and years 
with the current employer. The data base also included information on the type of appointment held (fixed term versus permanent) and on certain other aspects of the terms of employment. The data base has been updated to include information on job terminations and job commencements, as well as some information on changes in the terms of employment. All of the information used to update the base was derived from forms that employers were required to file in connection with maintenance of social insurance records (the so-called M1, M2, and M3 forms). It contains the information on the starting and ending date of an employment spell, the type of appointment, occupation, employer identification code, and personal characteristics (gender, age, and education).

(b) Unemployment data base (maintained by the Employment Office of Slovenia) contains all records of workers registering at employment offices after 1.1. 1992. Information includes the starting and ending date of unemployment, personal characteristics, as well as information about the receipt of unemployment benefits.

(c) Workers' earnings data base (maintained by the Pension and Disability Fund) contains information on earnings associated with each employment spell of workers employed in the formal sector. For each year (or part of the employment spell within a year) the information collected includes, among others, the amount of earnings, the number of hours worked in regular time and overtime, and starting and ending date of earnings period.

\section{Simulation Results}

In this section we describe the results of the simulation of the UISA system for Slovenia, obtained by applying the above-described algorithm to two simulation samples, one pertaining to the generous and one to the modest benefit regime (see Appendix 2 for the details of calculation of simulated variables). Below we report two sets of results -- one about the viability of the 
UISA system and the other about the changes in redistribution of income implied by the substitution of the traditional UI by the UISA system. Besides presenting the results under the baseline values for the parameters of the UISA system, we also report the results of sensitivity analysis produced by modifications of baseline values. Because the results are sensitive to the selection of "parents" (workers whose work histories are used to form a life-time work history of individuals selected in the simulation cohort), we repeated each type of simulation 10 times and generated average values for the quantities we wanted to evaluate, together with their standard errors.

The following values of the UISA simulation parameters were used for the baseline simulation:

- contribution rate: 3 percent of person's current wage;

- maximum accumulation amount: 3.9 average wages (that is, the amount that would cover a 6-month unemployment spell of a worker earning an average wage);

- maximum duration of benefits: we assumed that under UISA, the length of the receipt of unemployment benefits stayed the same as it occurred historically when the benefit was provided under UI (see above for the values of maximum potential durations of UI beneficiaries in Slovenia). That is, we assumed that all recipients received benefits for exactly the same length as they actually received them under the UI system;

- replacement rate: for UI benefits, 70 percent in the first three months, 60 percent thereafter; for unemployment assistance, 14.5 percent of the average wage (an average amount historically paid to UA assistance beneficiaries in Slovenia);

- minimum prior employment requirement: 6 months in the last 12 months;

- $\quad$ no grace period; and 
- interest rate: 2 percent.

Note that in line with our focus on generous and modest regime, we generated one baseline case for each regime. It also has to be remembered that whenever we compare the performance of the UISA and UI systems, we assume that under both systems the individual is offered exactly the same benefits (the same level and maximum duration of benefits), that is, that all behavioral changes are assumed away.

\section{(a) Viability of the UISA system}

Simulations show that the UISA system is a viable alternative to a modest UI system, but that its viability is jeopardized under generous benefits. In our baseline UISAs case, just about half of the workers end their working life with negative cumulative balance under the generous benefit regime, and less than a quarter under the modest regime (Table 1). The proportion of workers with a negative account balance at least once during their working life is also substantially larger under the generous regime, amounting to 66 percent and 43 percent for the generous and modest regimes, respectively. Moreover, under the modest benefit regime the workers are also better able to recover from temporary experiencing negative UISA balance than under the generous regime -- the ratio of workers with a negative terminal balance to the workers with ever negative balance is 0.58 under the modest compared to 0.74 under the generous regime. The UISA system, therefore, seems to work better under the modest benefit regime than under the generous regime, when a substantially less workers end their working careers with negative terminal balances as well as ever experience negative balances on their UISAs, and when there is a larger share of workers who are able to overturn their negative UISA balance into a surplus by the end of their working career. 
That the UISAs perform better under the modest benefit regime is confirmed also by the distribution of negative balances at retirement. Under the modest benefit regime, about half of individuals end their working careers with negative balances smaller than a 5-fold of national monthly wage, and another quarter with balances between 10- and 5-fold (Figure 1). In contrast, under the generous benefit regime over half of individuals end their working life with negative balance of more than a 10-fold of national monthly wage.

To learn more about the functioning of the UISAs, it is instructive to examine the relative performance of various groups. Under the generous regime, the likelihood of men to ever experience negative balances as well as to have a negative terminal exceeds the likelihood of these events for women; in contrast, under the modest regime, the same share of women and men experience negative UISA balance, but fewer women than men end their working life with the negative balance (20 vs. 29 percent, respectively; see Table 1). As far as education is concerned, the higher the education of workers, the lesser is the likelihood that they end their working careers with negative balances, as well as that these balances are ever negative (Table 1). But because the wages and hence benefits of more educated workers are higher, their accumulated balances at the end of working career are higher than those of less educated (Figure 1).

Additional insights are obtained by examining the accumulation of negative balances on the UISA by age of workers (Figure 2). Under the modest benefit regime, the percent of workers with negative balances rises with age, reaches its first peak at 13 percent in the 25-29-year bracket, gradually diminishes thereafter, and then sharply rises again after the age of 50; the share of women is higher except at the age of 55 and over. Under the generous benefit regime, the age profile of workers with negative balances is much steeper at the beginning of working career, it stabilizes between the age of 25 and 45 at 20 percent, and steeply rises again thereafter, 
reaching 50 percent in the 60-64 bracket. Interestingly, under the generous benefit regime the outcomes are similar for both genders, except at the age of over 55, when the fraction of men with negative balance continue to rise, while women's stagnates (reflecting their earlier withdrawal from the labor force). ${ }^{5}$

Reflecting differences in generosity of benefits, the average negative UISA balance at retirement is much higher under the generous than under the modest regime (Table 2). This balance amounts to a 14-fold of average monthly wage under the generous and 8-fold under the modest regime. ${ }^{6}$ While differences in the average negative UISA balance at retirement among men and women are not pronounced, more educated workers accumulate more negative balance than less educated under both regimes, perhaps reflecting higher wages earned by more educated workers (Table 2 and Figure 1).

Better performance of the UISAs under a modest benefit regime is confirmed also by results about self-financing of unemployment benefits. As shown in Table 2, under the modest benefit regime, 59 percent of the benefits are self-financed -- paid from individual UISAs, and only 42 percent under the generous benefit regime (recall that it is assumed that benefits are paid also when the UISA balance is negative, and that the government pays the debt of the workers who retire with negative balances on their UISA accounts). While the percent of self-financing does not differ much for men and women, more educated workers finance higher fractions of their benefits from their UISAs.

\footnotetext{
${ }^{5}$ For the comparison of labor market outcomes of men in women during early transition in Slovenia, see Orazem and Vopopivec (1995).

${ }^{6}$ Note that the average value of lifetime unemployment benefits is 11.5 and 4.7 multiple of average monthly wages under the generous and modest benefit regime, respectively.
} 
Could disincentives to return to formal sector employment after experiencing an unemployment spell - in cases when individuals have to repay large debt incurred by withdrawals from their UISAs - be overturned by using the retirement savings as the collateral? Figure 3 shows that, combined with a three-year grace period, contribution rates of 15-20 percent - which are quite usual for European pension systems - would indeed reduce the number of individuals with negative balances on their UISA below 5 percent under the modest, and below 10 percent under the generous, benefit regime - but only for individuals below the age of 50. Thereafter, the share of persons with negative UISA balance increases, particularly strongly under the generous benefit regime, exceeding 15 percent, and even 35 percent, for the age over 60 for the modest and generous regimes, respectively. This means that using pension contributions as collateral would work (that is, only few individuals would have the incentive not to return to the formal sector work) under the modest benefit regime and only until individuals reach the age of 50. That using pension as collateral makes sense was confirmed also by Yun (2002) for Korea, and Vodopivec and Rejec (2003) for Estonia; note that both countries have a modest unemployment benefit systems. On the other hand, even under the generous regime, workers over 50 years of age could retain incentives to return to covered employment, if offered extended benefits - but of course, the viability of such a UISA scheme would be compromised by low self-financing ability of workers at that age.

Sensitivity analysis. How deviations from the baseline values of the UISA parameters affect selected measures of the viability of the UISA system? We analyze this question by presenting two graphs for each UISA parameter under consideration, for both generous and modest benefit regimes (Figure 4). One graph shows the fraction of workers with negative balances on their UISA at the end of their working life, as well as the fraction with negative 
balances at least once during their working life. The other graph shows the taxation rate needed to finance the benefits of the workers who end their working lives with negative balances. To bring the reduction of taxation rate under the UISAs into a sharp relief, in the same plot we also present the taxation rate needed under the traditional UI system to guarantee the same level of benefits (the comparison of the two taxation rates thus allows to gauge the extent of selffinancing occurring under the UISA system). The results are as follows:

Contribution rate. As expected, the larger the contribution rate, the lower the fraction of negative balances and the taxation rate (Figure 4a), with the relationship being non-linear (the marginal effects of increasing the contribution rate are decreasing). Because the UISA system is quite sensitive to such changes at the low end of the contribution range, our simulations suggest that even the introduction of a modest UISA system with one percent contribution rate reduces the taxation rate needed to finance unemployment benefits significantly, from 1.0 to 0.7 percent under the modest benefit regime, and from 2.5 to 1.9 under the generous benefit regime. (Note that at zero contribution rate, the UISA system converts to the traditional UI system, and that the taxation rates under the two systems are identical.) By the same token, increasing the contribution rate from 3 percent (the baseline case) to 5 percent only moderately reduces the percentages of workers who end their working lives with negative balances - from 25 to 20 percent, and from 50 to 45 percent, under the modest and generous benefit regimes, respectively. Replacement rate. The higher the replacement rates, the higher both the fraction of negative balances and the taxation rate (Figure $4 \mathrm{~b}$ ). If the baseline replacement rate is halved (reduced to 50 percent of the baseline value), the fraction of workers with negative terminal UISA balances is reduced from 49 to 34 percent under the generous, and from 25 to 12 percent under the modest benefit regime. The reduction in the taxation rate is even more dramatic - 
halving the replacement rates reduces the taxation rate from 1.4 to 0.4 under the generous, and from 0.4 to 0.1 percent under the modest benefit regime. In contrast to the effects of contribution rate, the replacement rate has more linear effect, both on the fraction of workers with negative account balances and particularly on the taxation rate.

Contribution waiver amount. The UISA system is sensitive to the limit on the maximum balance of UISAs necessary to waive contributions to the account (Figure 4c). If this limit is set low, the fraction of workers with negative account balances increases strongly, particularly under the modest regime, and there is also a strong increase of the taxation rate. But there seems to be a ceiling - at approximately 10 average wages - above which increasing the limit does not affect the performance of the UISA system (the saturation effect).

The length of the grace period. The possibility that, at the start of the working career, the government takes over completely the financing of unemployment benefits reduces the number of workers with negative UISA balances. For example, under the modest benefit regime, the percent of workers with ever negative UISA balances is reduced from 43 percent (no grace period) to 34 percent (five years grace period) and under the generous benefit regime, the corresponding reduction is from 67 to 57 percent (Figure 4d). But, interestingly, these strong effects relate only to the proportion of workers ever experiencing negative balance - the proportion of workers with negative terminal balances, and also the taxation rate, are hardly affected.

Interest rate. Finally, changes in the interest rates profoundly affect the UISA system outcomes, while generating interesting asymmetries (Figure 4.e). Raising the interest rate from 0 to 6 percent strongly reduces the percent of workers with terminal negative balances, as well as the percent of workers who ever "sink in the red," under both generous and modest regimes. 
Introducing negative interest rates (taxing those with positive balances and subsidizing those with negative balances, as is sometimes the case in countries with repressed financial markets), however, does not affect these percentages. As expected, raising the interest rate decreases the required taxation rates, with the effects being very dramatic, particularly under the generous regime. Interestingly, this result applies over the whole relevant range of interest rates, that is, for positive as well as negative values of the interest rate.

\section{(b) Redistribution under UISA and UI}

If the traditional UI is replaced by the UISA system, how does this substitution change the redistribution of income implied by the UI system? It is the reduction of redistribution - leading to self-policing - which is central to the idea of UISA, and so under the extreme version with no negative balances, the system allows no redistribution. In our simulations, however, we allow individuals to borrow from their UISAs. As a consequence, as we showed above, some individuals end their working lives with negative balances which are financed by general taxes hence under the UISAs cum borrowing, (some) redistribution occurs, too.

Below we compare the redistribution of income under the UISAs to the one under the UI by simulating both systems on our sample of hypothetical individuals under both generous and modest benefit regime. As we show below, the type of UISA system studied here entails some redistribution from the rich to the poor, but substantially less than the traditional UI system. Unsurprisingly, the UISAs allows for relatively more redistribution (in comparison to the UI system) under the generous benefit regime (when the demand for benefits is higher), as well as under the specifications of the system which make the benefits more generous or require less savings to be accumulated on UISAs. In such cases, the taxation rate required to finance benefits 
is higher, as the government has to repay a larger debt arising from financing benefits with negative terminal balances.

In Tables 3 and 4 we present redistribution occurring under UISAs and UI for our baseline simulation cases, for both generous and modest benefit regimes. ${ }^{7}$ Beside lifetime wages, taxes, and unemployment benefits, we also present, for the UISA system, lifetime contributions to and terminal balance on UISAs, by wage quintiles (all variables are expressed in averages of national monthly wages). Note that by assumption, the level of unemployment benefits (for individuals, and, consequently, in aggregate) under both systems are identical. We focus on two measures of redistribution: net unemployment benefits and the ubsidization/taxation rate. Net unemployment benefits are calculated as the difference between lifetime unemployment benefits and lifetime taxes (the latter are augmented, under the UISAs, by the difference between lifetime contributions and terminal balances). Subsidization/taxation rate is defined as the ratio between net lifetime unemployment benefits and lifetime taxes (the latter are again augmented, under the UISAs, by the difference between lifetime contributions and terminal balances).

The level of redistribution (as measured by net unemployment benefits and the subsidization/taxation rate, by different quintiles) under the traditional UI system exceeds the one under the UISA system, particularly under the modest benefit regime (see Tables 4 and 5, and Figure 5). Under both UISAs and UI, individuals with high wages (particularly those in the two highest quintiles of their lifetime wages) are subsidizing individuals in the bottom quintiles, but the amount of redistribution and corresponding subsidization/taxation rates are much larger

\footnotetext{
${ }^{7}$ The baseline case for UI retains the same structure end eligibility conditions of benefits as they are under the UISA (60 percent replacement rate, the maximum duration of benefits of 6 months, minimum prior work requirement of 6 months in the last 12 months) and computes the implied taxation rate.
} 
under the UI system. For example, under the UI system and modest benefit regime, total unemployment benefits received by the poorest quintile exceed their own payments into the system by 251 percent, and the taxation rate of the richest quintile is 70 percent (that is, 70 percent of their payments into the UI system are used for payments of benefits outside their quintile); in contrast, the corresponding numbers under the UISAs are much lower, 76 and 49 percent, respectively. Under the generous benefit regime, the absolute amount of redistribution (as measured by net benefits) becomes larger under both the UISAs and UI systems, and while the subsidization rate under the UISAs increases, it decreases under the UI system (because of low payment of taxes under the modest regime). Still, even under generous benefit regime, the level of redistribution under the UISAs lags substantially behind the level of redistribution under the UI system.

Sensitivity analysis. To analyze how redistribution is affected by changes in key parameters of the UISA system, we show in Figures 6.a - 6.d the results of varying the parameters of the baseline simulation, one at the time.

Simulation results show that both under the generous and modest benefit regimes, increasing the contribution rate, the maximum balance of UISAs necessary to waive contributions to the account, or the interest rate decreases the redistribution under the UISA system (Figures 6a, 6b, and 6c). The effects of varying the contribution and the interest rates are particularly strong under the modest benefit regime, and for the variation of the maximum balance necessary to waive contributions, this effect only applies for values not exceeding the accumulation of 6 average monthly wages. This relationship is driven by the fact that increasing the abovementioned parameters of the UISA system increases the amount accumulated on individuals' UISAs, thus reducing the share of benefits to be financed by taxes. 
The results also show that the higher the replacement rate, the more redistribution is implied by the UISA system under both modest and generous benefit regimes (Figures 6d). In these cases, the effect is produced by the increase in the generosity of the benefits; under unchanged UISA financing parameters, this increase calls for higher taxes and hence more redistribution.

\section{Concluding Remarks}

By simulating the working of the UISA system in Slovenia, the paper examined how viable is this system as an alternative to traditional UI system, and how the redistribution of income changes if the UISA replaced the UI system. Assuming a 3 percent contribution rate and a 6070 percent replacement rate, our calculations show that, under the modest benefit regime, one quarter of workers end their working life with negative cumulative balance and 44 percent ever experience a negative UISA balance; in contrast, under the generous regime, 50 percent of workers end their working life with negative cumulative balance and 67 percent ever experience a negative balance.

While according to our simulations, the shares of workers for whom UISAs would "not work” are higher than the shares reported by Feldstein and Altman (1998) for the US (see above), these results could be interpreted as favorable to the introduction of the UISA system under the modest benefit regime. First, our simulations of even modest system assume higher replacement rate and longer entitlement periods then those offered by the US system, and we assume a 3 percent contribution rate (Feldstein and Altman assume 4 percent). According to our sensitivity analysis, reducing the replacement rate to 50 percent and increasing the contribution rate to 4 percent would reduce the share of workers who end their working life with negative 
terminal UISA balance by about 8 percentage points, and further reductions would be obtained by reducing potential duration of benefit. Second, using pension contributions as collateral would strongly improve the incentives not to withdraw from the system once the individual incurs maximum indebtedness, thus removing a potentially important obstacle to the viability of the UISA system (and given the small share of unemployment benefits in lifetime earnings, such an arrangement would not undermine a pension system). It has to be emphasized that the above simulations do not account for any behavioral changes and that by doing so, they underestimate the viability of the system - after all, improved reemployment incentives are the main rationale for introducing the UISA system. But under the generous regime, the share of workers who could not be self-protect against the risk of unemployment is much larger, and therefore the UISA a much less attractive option.

The paper also found that the substitution of the traditional UI with the UISA system reduces redistribution and thus hurts the poor. Although the version of the UISA system studied in the paper permits borrowing from such accounts and thus allows for redistribution of income (in our analysis, from individuals in the top to those in the bottom quintiles of lifetime wage distribution), the level of redistribution lags substantially behind the level which occurs under the UI system. While both UI and UISA generate more redistribution under the generous benefit regime, the gap between the two is particularly large under the modest regime, reflecting precisely the fact that workers are more to able to finance their own unemployment benefits if their level is modest.

Ultimately, the choice between the UI and UISA system may thus entail weighing the benefits of reducing moral hazard (higher job-finding rate among the recipients and thus reduced unemployment rate, coupled by lower overall costs of unemployment benefits that may stimulate 
employment generation) and the costs of reduced net transfers implied by the introduction of the UISA system, mostly borne by those at the lower points of income distribution in terms of their reduced consumption. ${ }^{8}$

Our other results suggest that by allowing workers to draw benefits even when the balance on their account falls below zero, the consumption smoothing properties of the UISA system are significantly improved, and that a many of these workers subsequently repay their UISA debts. ${ }^{9}$ The above results also suggest that the UISA system is quite sensitive to changes in its parameter values. For example, setting a low contribution rate is likely to cause that a significant fraction of workers end their working careers with negative balances on their UISAs accounts, and require a relatively large taxation rate.

\footnotetext{
${ }^{8}$ The presence of moral hazard problems in the Slovenian UI system has been shown by van Ours and Vodopivec (2006), who take advantage of the 1998 change of the UI law which reduced potential benefit durations and show that following the change, the probability of leaving unemployment significantly increased.

${ }^{9}$ Compare the results of Hopenhayn and Hatchondo (2002), who study the design of UISA accounts by considering welfare effects of different parameter specification. Their main finding is that UISA can come close to the full insurance and optimal UI cases, and that UISAs performance along efficiency/budget deficit tradeoff is the maximized under high taxation and low replacement rates.
} 


\section{References}

Cortazar, R. (1996). “Sharing Risk in Volatile Labour Markets.” In R. Housmann, and H. Reisen, eds., Securing Stability and Growth in Latin America, Policy Issues and Prospects for Shock-Prone Economics. Paris: OECD.

Feldstein, Martin, and Daniel Altman (1998). Unemployment Insurance Savings Accounts. NBER Working Paper No. 6860.

Gill, I.S., E. Haindl, C. E. Montenegro, and C. N. Sapelli (2000). Chile: Has Employment Become more Precarious?", in I.S. Gill and C.E. Montenegro, eds., "Readdressing Latin America's "Forgotten Reform:" Quantifying Policy Changes in Argentina, Brazil, and Chile," World Bank.

Heckman, J. J., and C. Pages (2000). "The Cost of Job Security Regulation: Evidence from Latin American Labor Markets.” NBER Working Paper No. 7773.

Haltiwanger, C. J., and M. Vodopivec (2002). Gross Worker and Job Flows in a Transition Economy: An Analysis of Estonia, Labour Economics, Vol. 9, No. 5, pp. 601-630.

Hopenhayn H. and J. Hatchondo (2002). The Welfare Consequences of Alternative Designs of Unemployment Insurance Savings Accounts, University of Rochester, processed.

Kugler, A. (2000). “Severance Payments Savings Accounts: Evidence from Colombia.” Universitat Pompeu Fabra, processed (prepared for the World Bank).

Lipsett, Brenda (1999). Supporting Workers in Transition: Income Support Programs for the Unemployed in Brazil and Argentina. Prepared for HDNSP, World Bank.

Meyer, B. D. (1995). "Lessons from the U.S. Unemployment Insurance Experiments," Journal of Economic Literature, Vol. 33, 91-131.

Mortensen, D. T. (1994). Reducing Supply-side Disincentives to Job Creation. Paper presented at Federal Reserve Bank of Kansas City Symposium "Reducing Unemployment: Current Issues and Policy Options,” Jackson Hole, Wyoming, August 25-27, 1994.

Orazem, P. and M. Vodopivec (2000). "Male-Female Differences in Labor Market Outcomes During the Early Transition to Market: The Cases of Estonia and Slovenia." Journal of Population Economics, Vol. 13, pp. 283-303.

Orszag, J. Michael, et al (1999). The Impact of Individual Accounts: Piecemeal vs. Comprehensive Approaches. Paper presented at the Annual Bank Conference on Development Economics, World Bank, April 29, 1999.

Orszag, J. Michael, and Dennis Snower (1997). From Unemployment Benefits to Unemployment Support Accounts. Available at: http://www.econ.bbk.uk/ukcosts/incentives.html.

Statistical Office of Estonia, 1998. Methodological Report on 1997 Estonian Labour Force Survey. Tallinn 1998. 
J.C. van Ours and M. Vodopivec (2006) How Shortening the Potential Duration of Unemployment Benefits Affects the Duration of Unemployment: Evidence from a Natural Experiment. Journal of Labor Economics, 24 (2): 351:378.

Vodopivec, M. (2002). Worker Reallocation During Estonian Transition To Market, International Journal of Manpower, Vol. 23, No.1. pp. 77-97.

Vodopivec, M. (2004). Income Support for the Unemployed: Issues and Options, The World Bank, Regional and Sectoral Studies Series.

Vodopivec M., A. Wörgötter and D. Raju ( 2005). Unemployment Benefit Systems in Central and Eastern Europe: a Review of the 1990s, Comparative Economic Studies 47(4): 615651.

Yun, J. (2002). An Empirical Simulation for the Relevance of Alternative Systems to Unemployment Insurance in Korea, Ewha University, processed, 21p.

Yun, J. (2001). "On the Integration of Unemployment Insurance with Pension through Individual Savings Account.” World Bank, Human Development Network, Washington, DC. 
Table 1: Share of workers with negative balance on their UISA (in percent)*

\begin{tabular}{|l|c|c|c|c|}
\hline \multirow{2}{*}{} & \multicolumn{3}{|c|}{ Negative balance at retirement } & \multicolumn{2}{c|}{$\begin{array}{c}\text { Ever negative balance } \\
\text { during the working life }\end{array}$} \\
\cline { 2 - 5 } & Generous regime & Modest regime & Generous regime & Modest regime \\
\hline Total & $49.2 \pm 0.9$ & $24.6 \pm 1.3$ & $66.3 \pm 1.6$ & $42.5 \pm 1.4$ \\
\hline Gender & $53.2 \pm 1.0$ & $28.6 \pm 1.9$ & $69.7 \pm 1.8$ & $42.0 \pm 2.1$ \\
\hline Males & $44.8 \pm 2.3$ & $20.2 \pm 1.6$ & $62.7 \pm 2.6$ & $43.0 \pm 1.8$ \\
\hline Females & & & \\
\hline & & & \\
\hline Education & $57.8 \pm 1.3$ & $30.5 \pm 2.7$ & $73.0 \pm 1.9$ & $44.4 \pm 2.9$ \\
\hline Vocational & $59.1 \pm 2.5$ & $30.5 \pm 3.0$ & $75.5 \pm 3.0$ & $50.7 \pm 2.9$ \\
\hline Middle & $21.7 \pm 2.7$ & $7.0 \pm 2.2$ & $43.0 \pm 3.1$ & $27.0 \pm 2.9$ \\
\hline University &
\end{tabular}

*Percentages with negative balances of the categories in the same row.

Table 2: The fraction of the benefits financed from UISAs and average negative balance at retirement

\begin{tabular}{|l|c|c|c|c|}
\hline \multirow{2}{*}{} & \multicolumn{1}{|c|}{$\begin{array}{c}\text { Average negative balance at } \\
\text { retirement } \\
\text { (in average monthly wages) }\end{array}$} & \multicolumn{2}{c|}{$\begin{array}{c}\text { Fraction financed from UISAs } \\
\text { (in percent) }\end{array}$} \\
\cline { 2 - 5 } & Generous regime & Modest regime & Generous regime & Modest regime \\
\hline Total & $13.5 \pm 0.6$ & $7.7 \pm 0.4$ & $41.6 \pm 1.2$ & $59.1 \pm 1.4$ \\
\hline \multirow{5}{*}{ Gender } & $14.0 \pm 0.8$ & $8.3 \pm 0.6$ & $41.8 \pm 1.6$ & $55.3 \pm 1.5$ \\
\hline Males & $13.0 \pm 0.9$ & $6.8 \pm 1.0$ & $41.5 \pm 2.1$ & $64.8 \pm 4.4$ \\
\hline Females & $10.1 \pm 0.5$ & $6.3 \pm 0.7$ & $43.9 \pm 1.3$ & $58.0 \pm 3.2$ \\
\hline \multirow{5}{*}{ Education } & $15.2 \pm 0.6$ & $8.4 \pm 0.2$ & $38.3 \pm 1.3$ & $56.6 \pm 1.7$ \\
\hline Vocational & $20.6 \pm 1.8$ & $11.9 \pm 3.6$ & $46.1 \pm 4.1$ & $70.8 \pm 7.2$ \\
\hline Middle &
\end{tabular}


Table 3: Redistribution under UISA, baseline case*

\begin{tabular}{|l|r|r|r|r|r|}
\hline & $1^{\text {st }}$ Quintile & $2^{\text {nd }}$ Quintile & $3^{\text {rd }}$ Quintile & $4^{\text {th }}$ Quintile & $5^{\text {th }}$ Quintile \\
\hline Generous regime & 147.1 & 288.5 & 393.9 & 528.6 & 956.8 \\
\hline Lifetime wages & 2.1 & 4.1 & 5.7 & 7.6 & 13.8 \\
\hline Lifetime taxes & 4.2 & 7.0 & 8.0 & 8.4 & 8.9 \\
\hline Lifetime UISA contributions & 10.3 & 13.1 & 13.3 & 11.4 & 8.8 \\
\hline Lifetime unempl. benefits & 1.0 & 1.6 & 2.2 & 3.1 & 4.8 \\
\hline Terminal UISA balance & 5.1 & 3.6 & 1.8 & -1.5 & -9.0 \\
\hline Net unemployment benefits & 96.8 & 37.3 & 15.4 & -11.3 & -50.7 \\
\hline Subsidization/taxation rate** & \multicolumn{7}{|c|}{} \\
\hline Modest regime & 133.1 & 279.1 & 386.2 & 532 & 949 \\
\hline Lifetime wages & 0.6 & 1.2 & 1.6 & 2.2 & 3.9 \\
\hline Lifetime taxes & 3.7 & 6.4 & 7.1 & 7.2 & 7.5 \\
\hline Lifetime UISA contributions & 4.7 & 5.5 & 5.6 & 4.4 & 2.9 \\
\hline Lifetime unempl. benefits & 1.6 & 3.0 & 3.6 & 4.5 & 5.7 \\
\hline Terminal UISA balance & 2.0 & 0.9 & 0.5 & -0.6 & -2.8 \\
\hline Net unemployment benefits & 75.5 & 18.6 & 9.9 & -11.8 & -49.4 \\
\hline Subsidization/taxation rate** & & & &
\end{tabular}

Notes:

* Except the ratio of lifetime taxes to lifetime unemployment benefits, other variables are expressed in multiples of the average national monthly wages.

** Subsidization/taxation rate is defined as $100 *(\mathrm{LUB}-\mathrm{LT}) / \mathrm{LT}=100 *(\mathrm{LUB} / \mathrm{LT}-1)$, where LUB is lifetime unemployment benefits and LT is lifetime taxes plus lifetime contributions minus terminal balances.

Table 4: Redistribution under UI, baseline case*

\begin{tabular}{|l|r|r|r|r|r|}
\hline & $1^{\text {st }}$ Quintile & $2^{\text {nd }}$ Quintile & $3^{\text {rd }}$ Quintile & $4^{\text {th }}$ Quintile & $5^{\text {th }}$ Quintile \\
\hline Generous regime & 147.1 & 288.5 & 393.9 & 528.6 & 956.8 \\
\hline Lifetime wages & 3.6 & 7.1 & 9.7 & 13.0 & 23.5 \\
\hline Lifetime taxes & 10.3 & 13.1 & 13.3 & 11.4 & 8.8 \\
\hline Lifetime unempl. benefits & 6.7 & 6.0 & 3.6 & -1.6 & -14.8 \\
\hline Net unemployment benefits & 185.5 & 85.2 & 37.1 & -12.2 & -62.7 \\
\hline Subsidization/taxation rate** & \multicolumn{7}{|l|}{} \\
\hline Modest regime & 133.1 & 279.1 & 386.2 & 532.0 & 949.0 \\
\hline Lifetime wages & 1.3 & 2.8 & 3.9 & 5.4 & 9.6 \\
\hline Lifetime taxes & 4.7 & 5.5 & 5.6 & 4.4 & 2.9 \\
\hline Lifetime unempl. benefits & 3.4 & 2.7 & 1.7 & -1.0 & -6.7 \\
\hline Net unemployment benefit & 250.6 & 94.6 & 42.7 & -18.8 & -69.7 \\
\hline Subsidization/taxation rate** & \multicolumn{7}{|l|}{${ }^{* *}$} &
\end{tabular}

Notes:

* The taxation rate is computed so as to cover the benefits on the pay-as-you-go basis. Except the subsidization/taxation rate, other variables are expressed in multiples of the average national monthly wages. **Subsidization/taxation rate is defined as $100 *(\mathrm{LUB}-\mathrm{LT}) / \mathrm{LT}=100 *(\mathrm{LUB} / \mathrm{LT}-1)$, where LUB is lifetime unemployment benefits and LT is lifetime taxes. 
Figure 1: Distribution of negative balances at retirement by gender and education
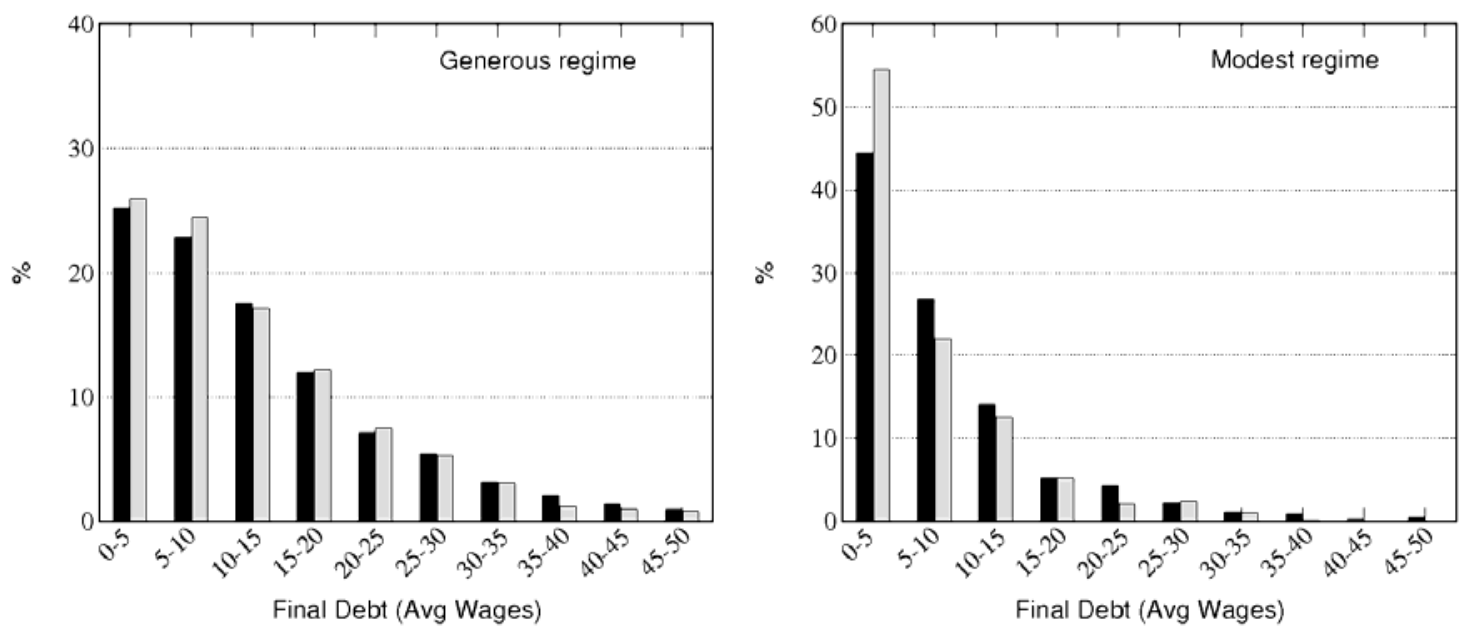

- Males

$\square$ Females
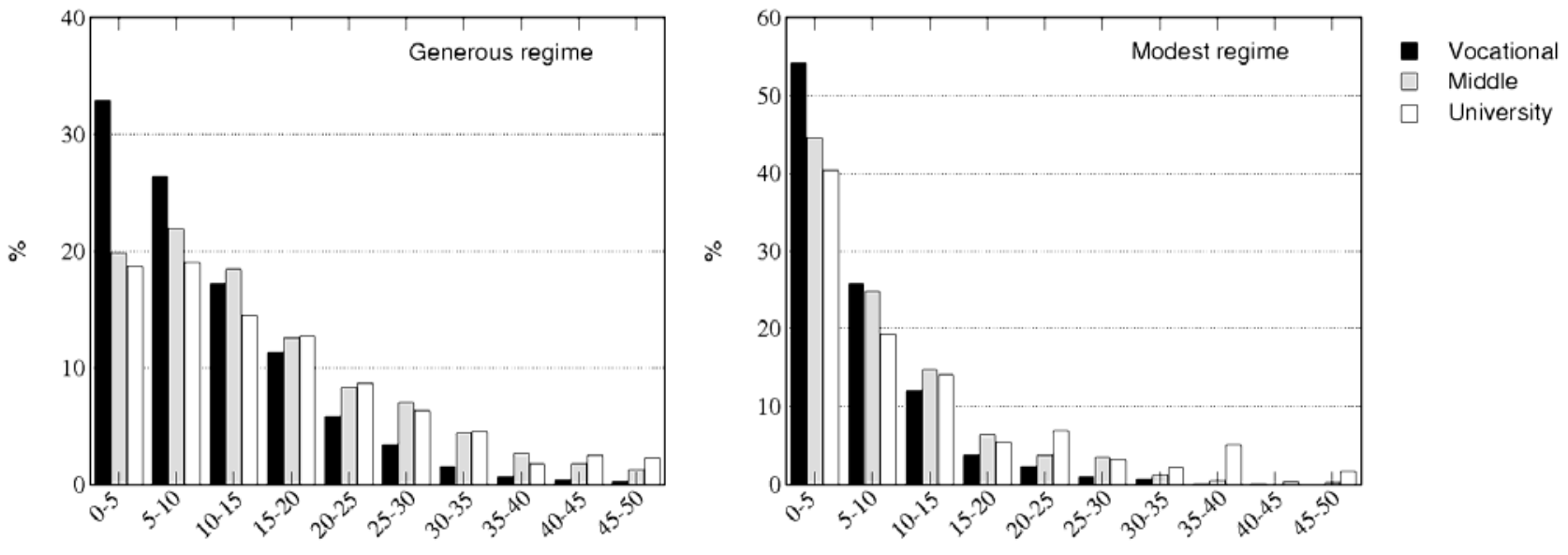

Final Debt (Avg Wages)

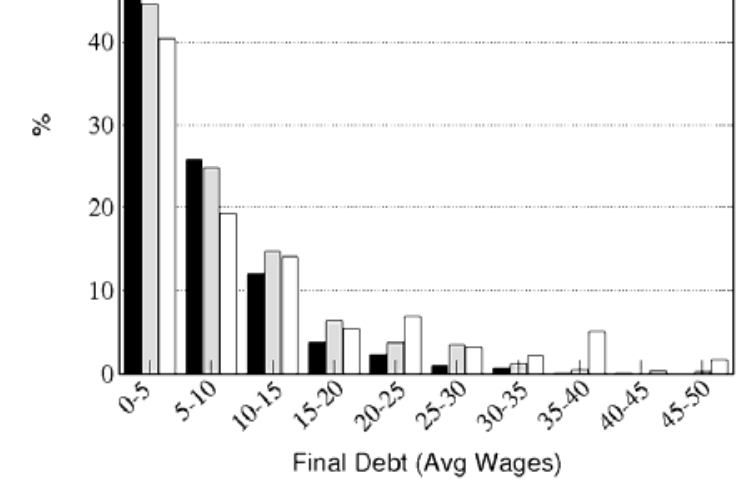
. 
Figure 2: Fraction of persons with a negative UISA balance, by age, gender and education, baseline parameter values
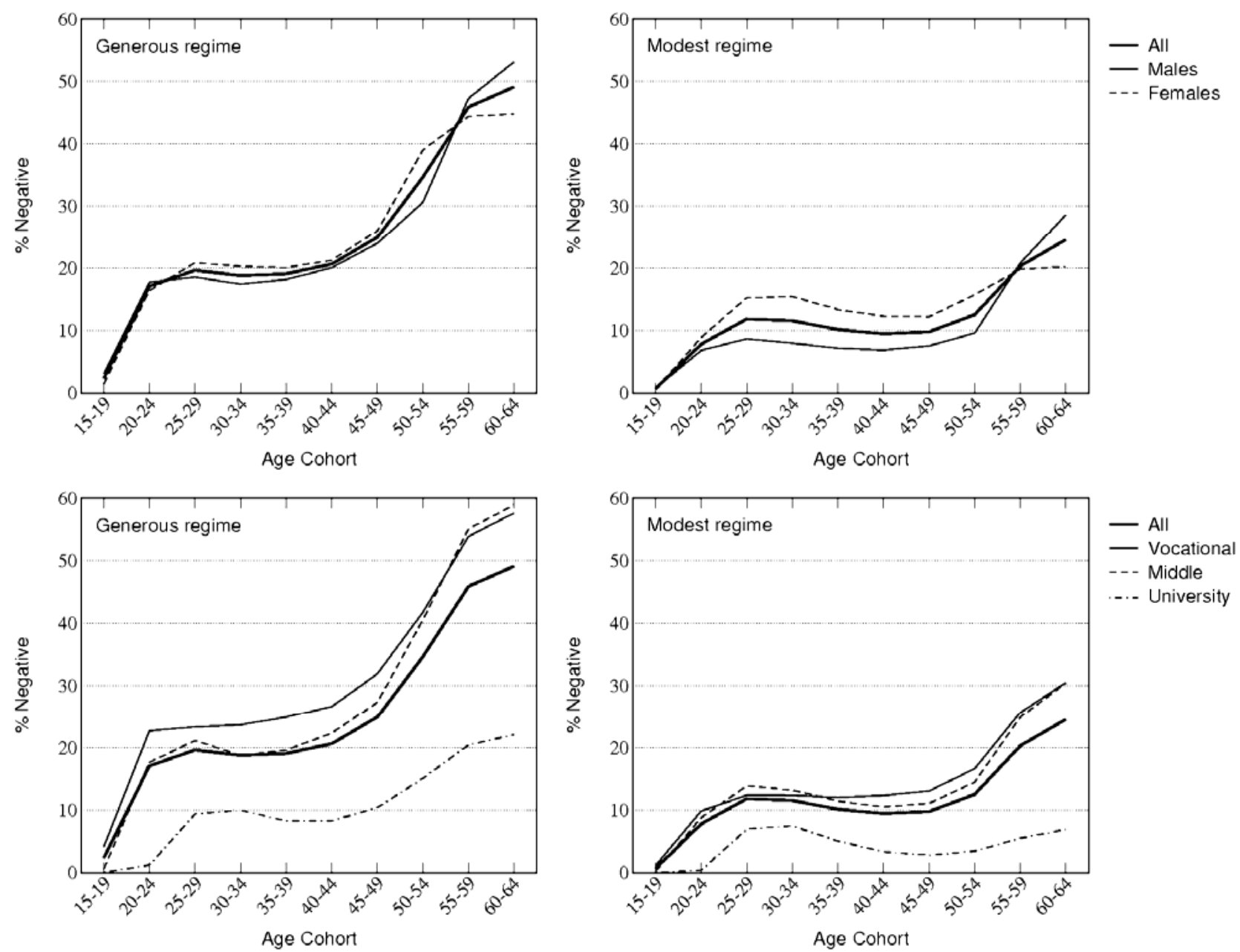

Figure 3: Fraction of persons with a negative UISA balance under different contribution rates, by age*
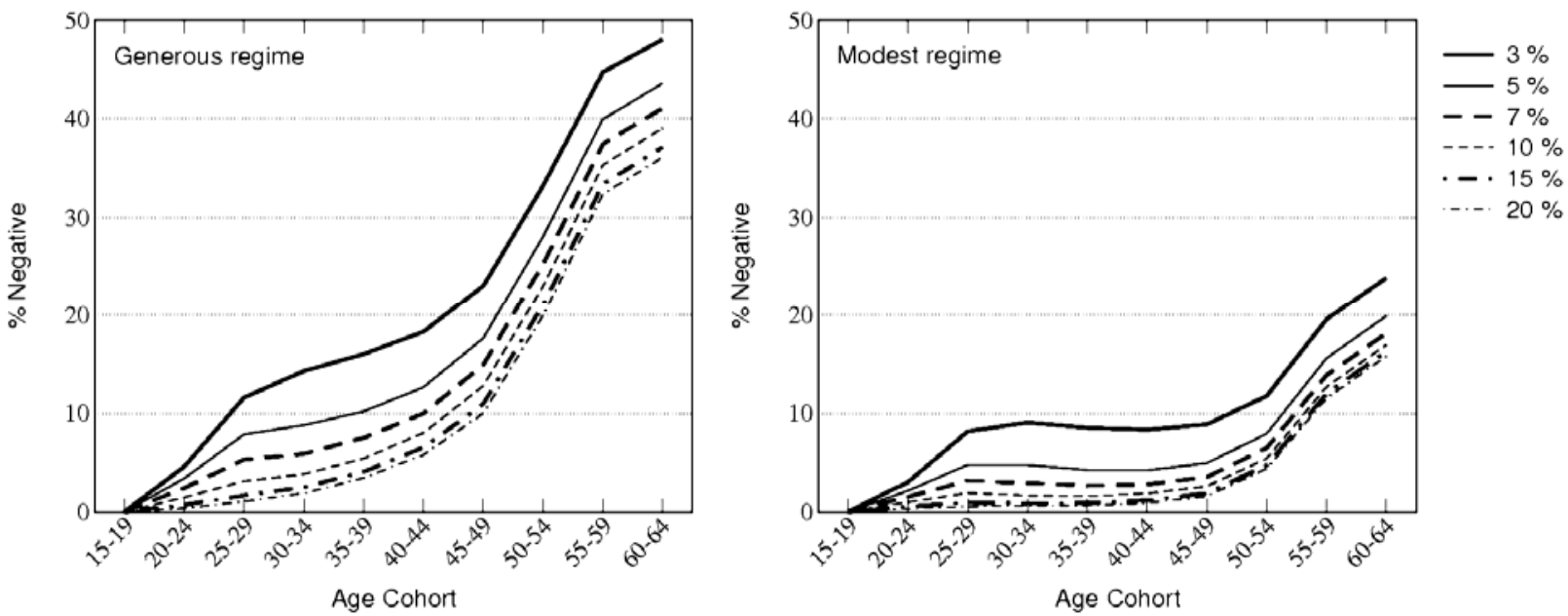

*Grace period: three years 
Figure 4: How the percentage of workers with negative balance and the taxation rate are affected by the parameters of UISA, generous and modest regimes

\section{(a) Contribution rate}
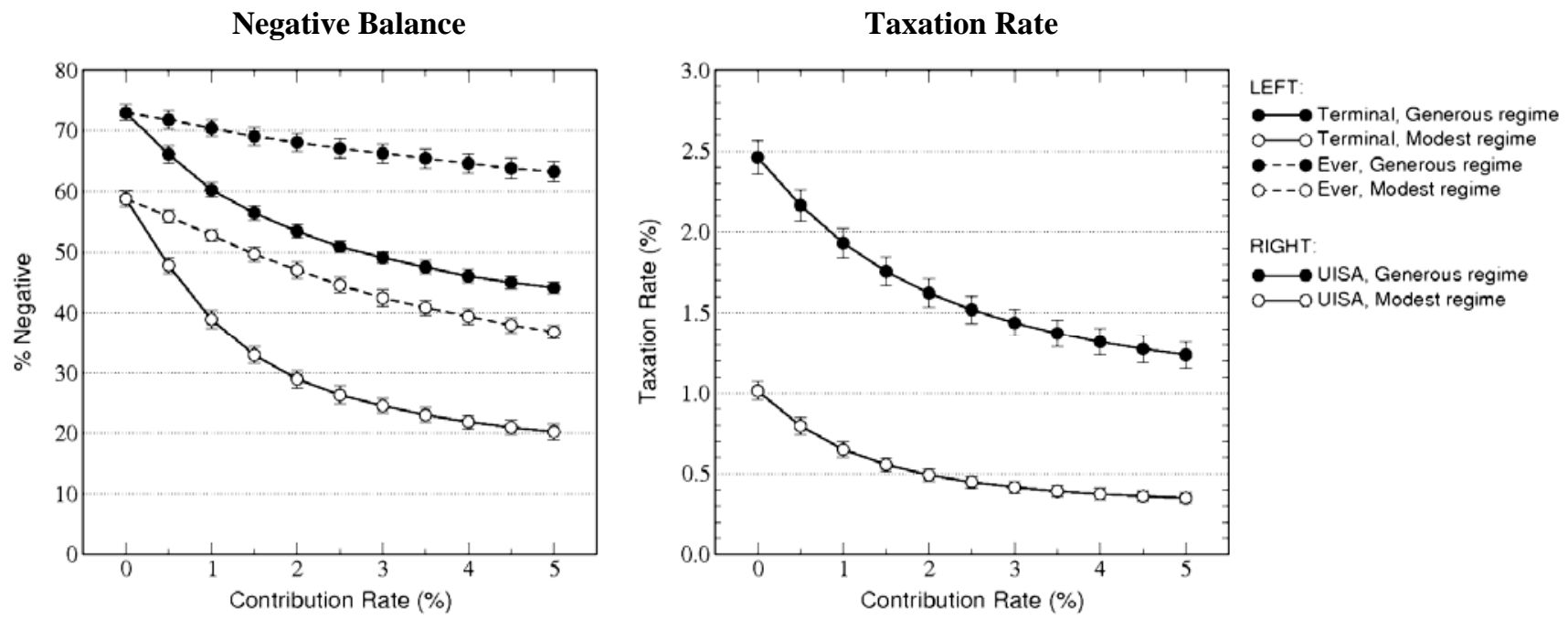

(b) Replacement rate
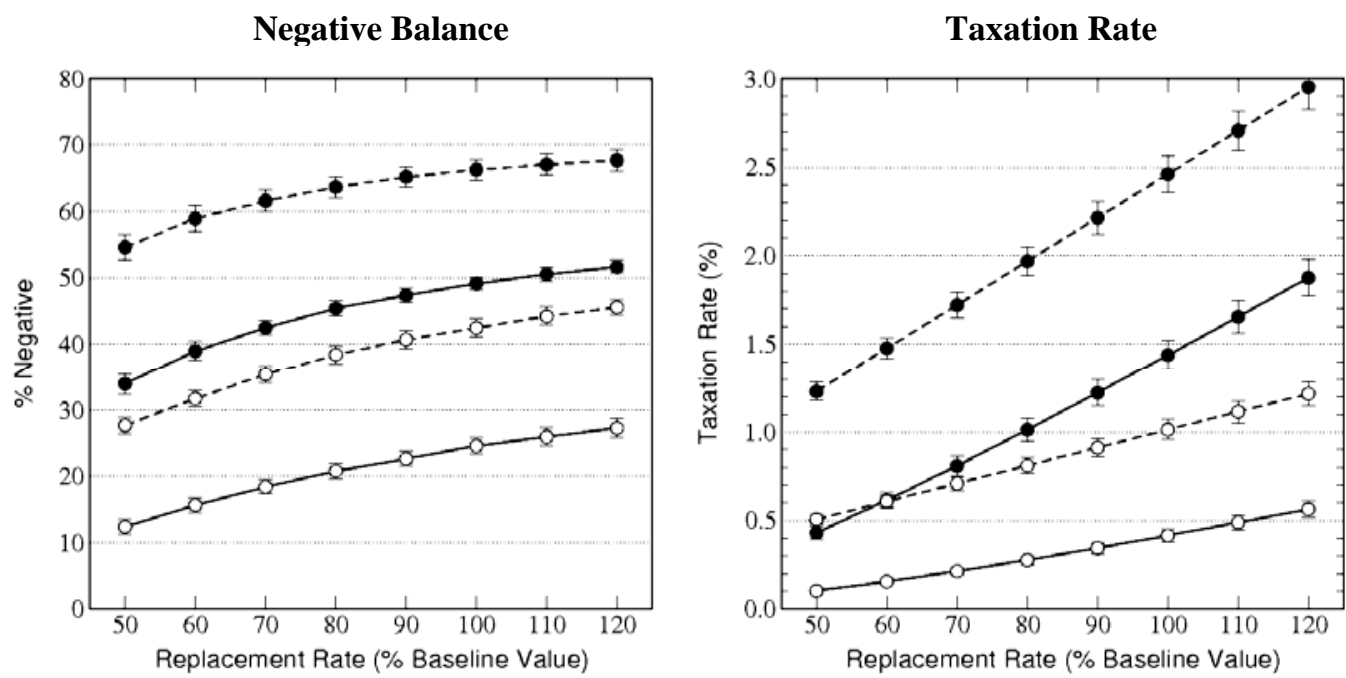

LEFT:

$\longrightarrow$ Terminal, Generous regime ○_ Terminal, Modest regime - - Ever, Generous regime - - O Ever, Modest regime RIGHT:

- UISA, Generous regime ○ O UISA, Modest regime - - - UI, Generous regime o--o UI, Modest regime 


\section{(c) Contribution waiver amount}

Negative Balance

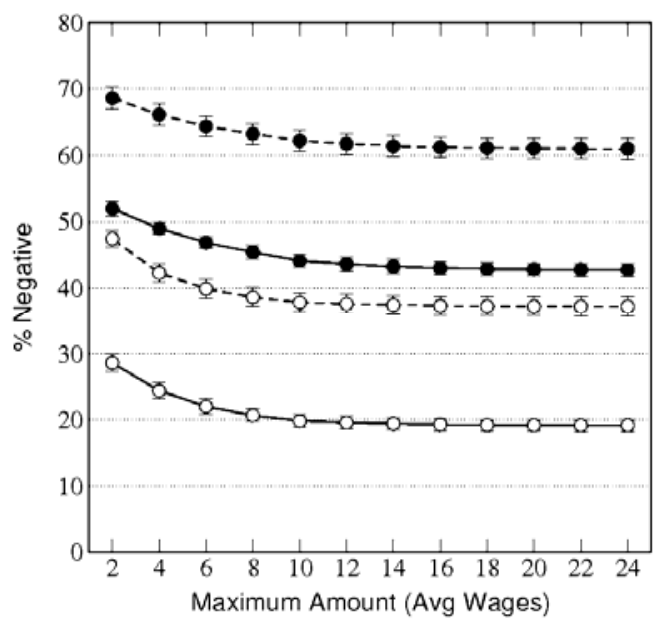

Taxation Rate

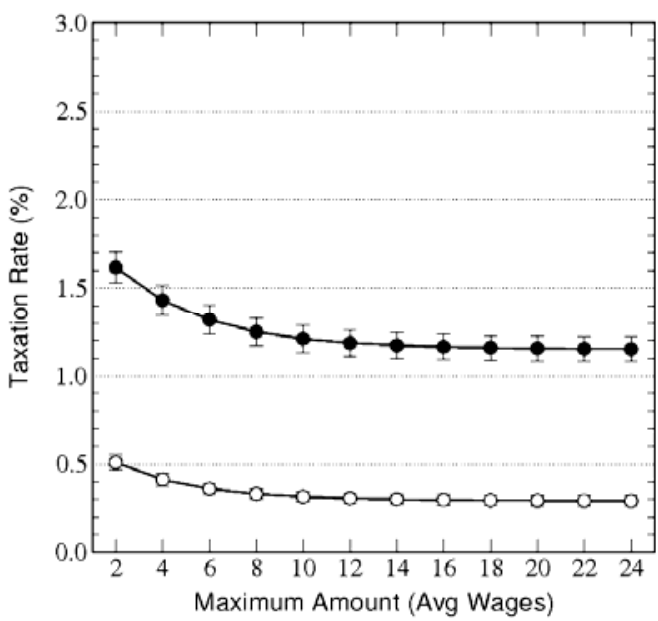

LEFT:

$\longrightarrow$ Terminal, Generous regime - Terminal, Modest regim

- - Ever, Generous regime

o-- o Ever, Modest regime

RIGHT

$\longrightarrow$ UISA, Generous regime — U UISA, Modest regime

\section{(d) Length of the grace period*}

Negative Balance

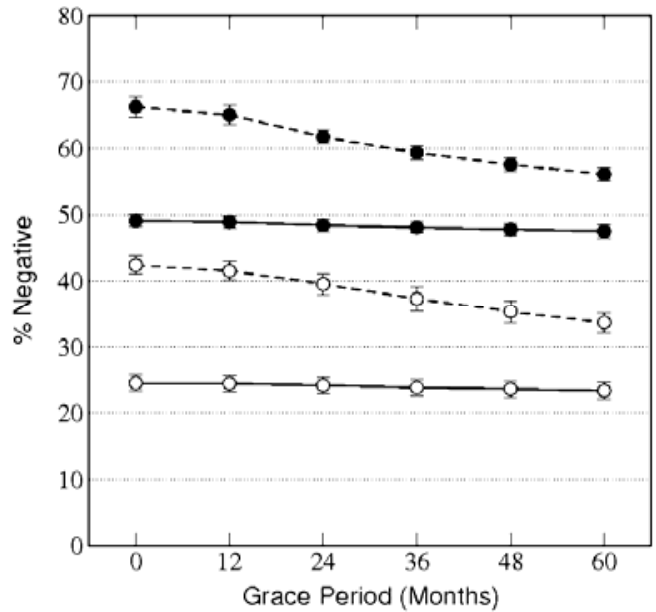

Taxation Rate

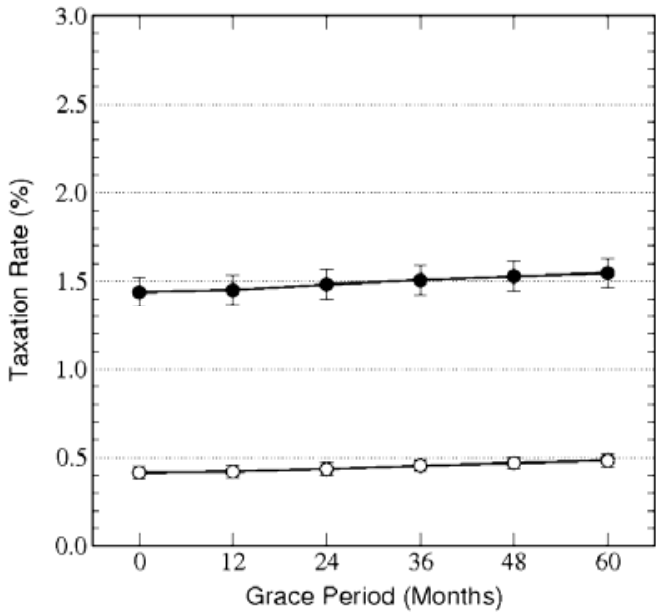

LEFT:

$\longrightarrow$ Terminal, Generous regime O- Terminal, Modest regime

- - Ever. Generous regime - - O Ever. Modest regime

RIGHT:

$\longrightarrow$ UISA, Generous regime

○ O UISA, Modest regime

* The receipt of benefits during the grace period does not affect UISA balances. 


\section{(e) Interest rate}
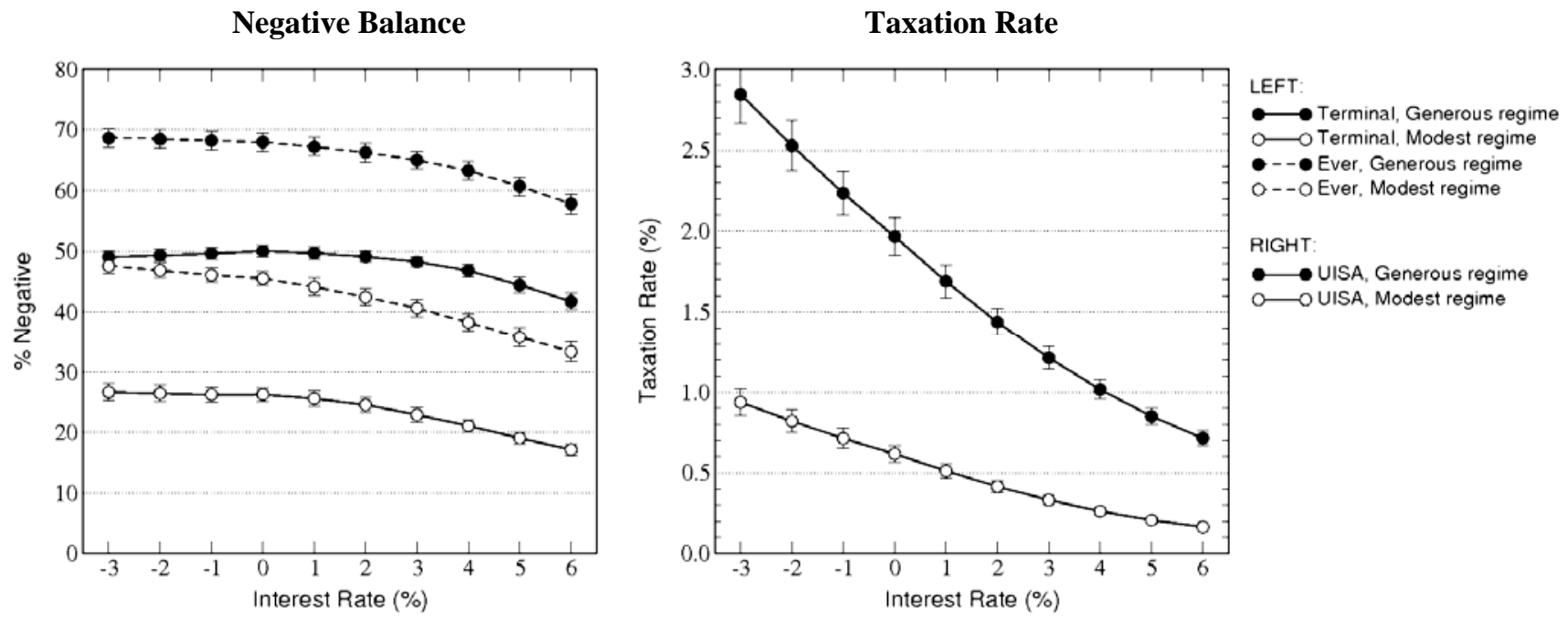

Figure 5: Comparison of subsidization/taxation rate implied by UISA and UI systems under generous and modest benefit regimes
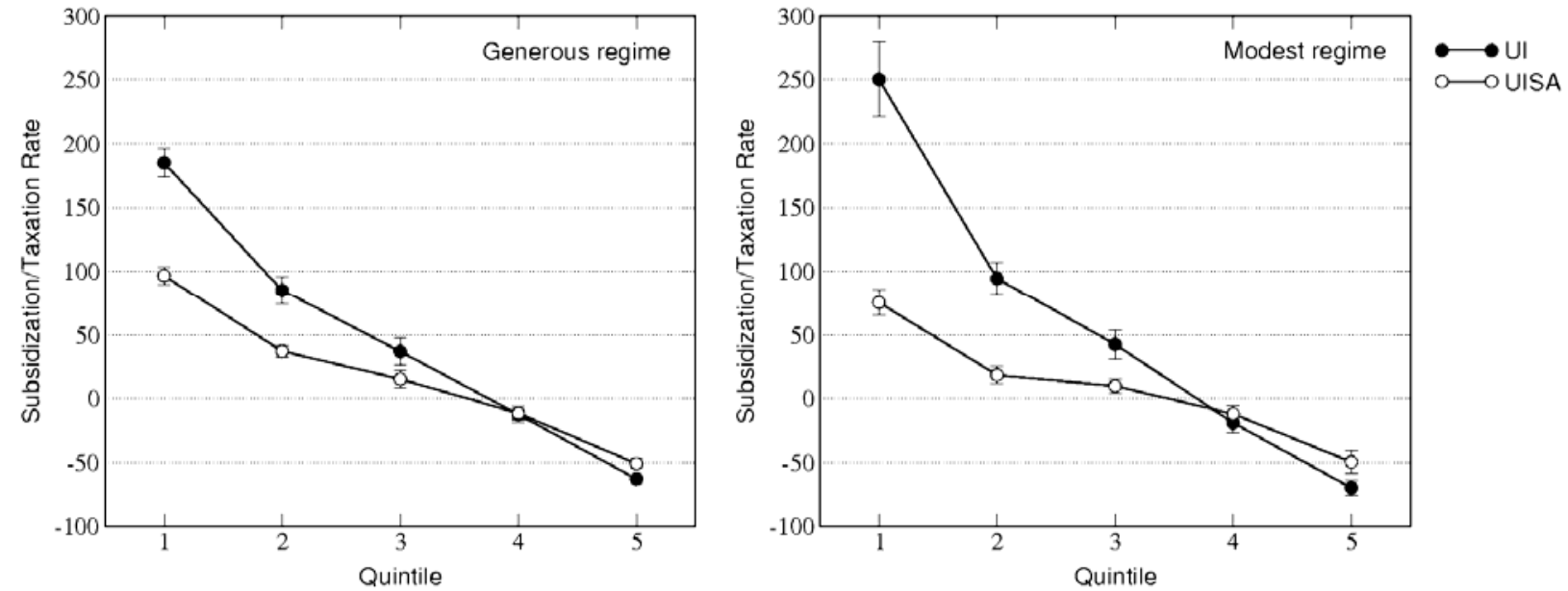
Figure 6: How subsidization/taxation rate under UISA is affected by changes of the system parameters, generous and modest regime

\section{(a) Contribution rate}
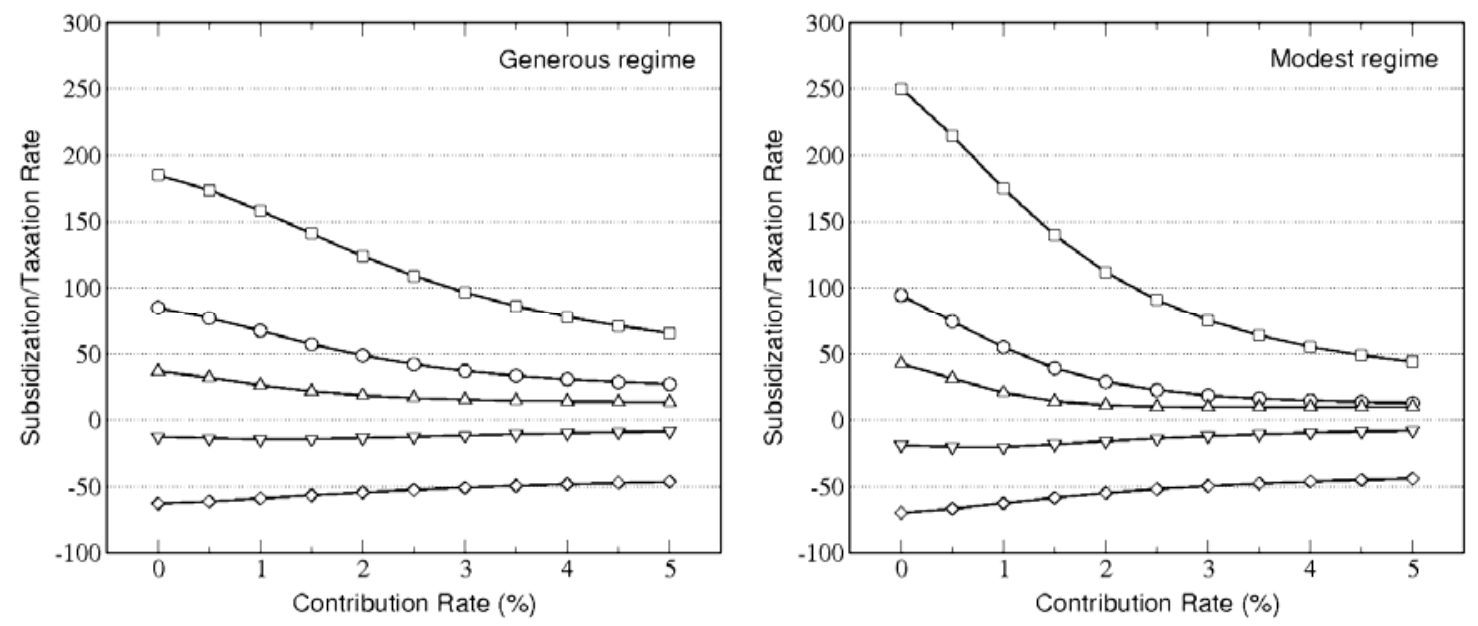

$\square 1^{\text {st }}$ Quintile
$\square 2^{\text {nd }}$ Quintile
$\square 3^{\text {td }}$ Quintile
$\square \longrightarrow 4^{\text {th }}$ Quintile
$\diamond \longrightarrow 5^{\text {th }}$ Quintile

(b) The maximum balance of UISAs necessary to waive contributions to the account
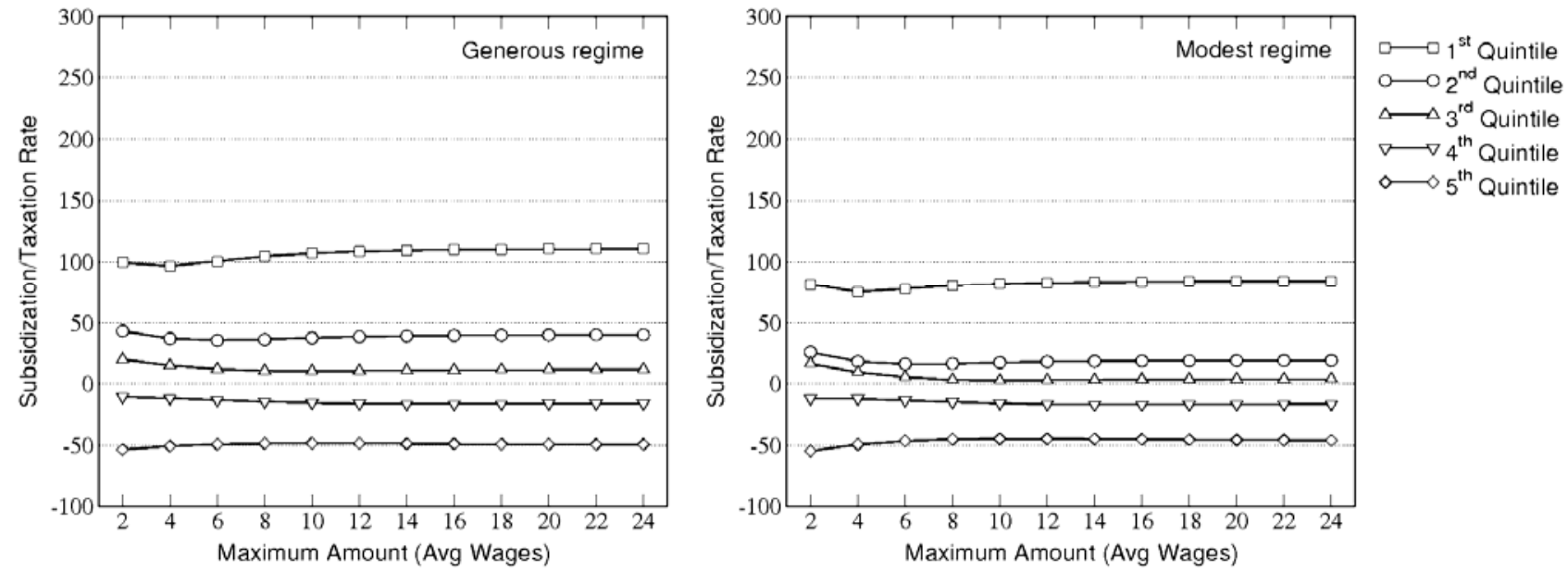


\section{(c) Interest rate}
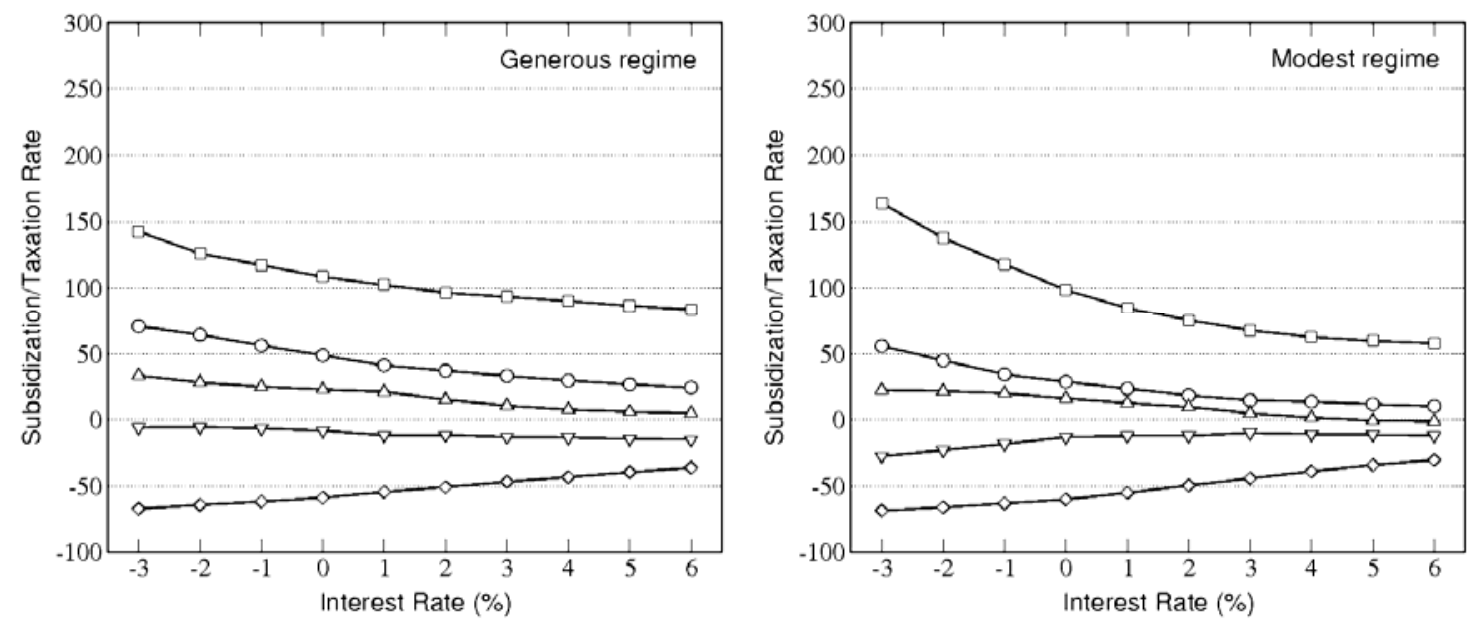

$\square 1^{\text {st }}$ Quintile
$\square 2^{\text {nd }}$ Quintile
$\square 3^{\text {td }}$ Quintile
$\square \longrightarrow 4^{\text {th }}$ Quintile
$\diamond 5^{\text {th }}$ Quintile

(d) Replacement rate
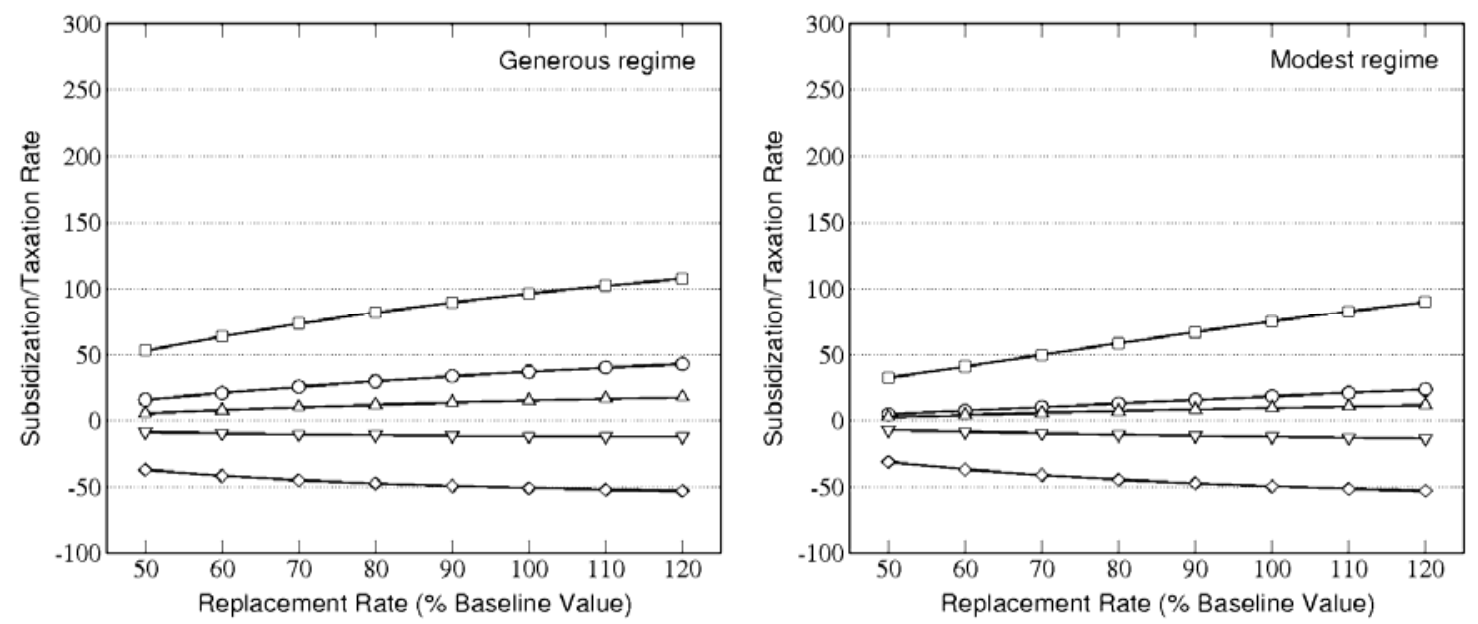

$\square 1^{\text {st }}$ Quintile
$\square 2^{\text {nd }}$ Quintile
$\longleftarrow 3^{\text {rd }}$ Quintile
$\square \longrightarrow 4^{\text {th }}$ Quintile
$\diamond 5^{\text {th }}$ Quintile 


\section{Appendix 1: Obtaining complete work histories for simulation cohorts}

Simulations of the UISA system rest on unusually rich administrative data bases covering all Slovenian workforce participants and all formal spells of employment and unemployment, together with accompanying earnings. To be able to simulate the working of the UISA system, we created a complete work history of two simulation cohorts (one for the generous and one for the modest regime), from the entry to the labor force until the withdrawal from it. Because the simulated period is much longer than the period covered by the data, we extrapolated the observed work of individuals selected in the cohort by work histories of workers who matched certain selection criteria (called hereafter parents). The sequential merging of data of several parents, spanning over a complete work life, produced a complete work history for each of the workers selected in the simulation cohort. To select the parents, we used the information about the work history of the whole Slovenian labor force. We used the 1995-1998 work histories to simulate the generous, and the 2000-01 work histories to simulate the modest benefit regime.

\section{Creating work history of the simulation cohort from the data on "parents"}

In each simulation cohort, we randomly selected 1000 individuals who entered labor force during the 1995-98 and 2000-01 periods for the generous and modest benefit regime, respectively. To extend the work history of the persons over their lifetime period, we then used the labor market history of "parents" pertaining to that period. We matched a spell of the parent to the spell of worker from the simulation cohort based on the following criteria:

- the parent being within two years of the age of the worker included in the simulation cohort,

- being of the same gender,

- $\quad$ having the same level of education within three education categories: vocational (which included unfinished elementary, elementary or vocational education), high school, and university (either two-year or four-year degree), and

- being the same type of spell: employment (with additional criteria that the corresponding wages should match within 10 percent), ${ }^{10}$ unemployment, or inactivity. In addition, unemployment spells were matched based on the recipient status (receiving unemployment benefit, receiving unemployment assistance, unemployment spell without benefits, unemployment spell after the end of a benefit) and length of that status (permitted were difference of less than 1 month for durations up to 3 months, less than 2 months for durations of up to 6 months, of less than 3 months for durations of up to 1 year, less than 6 months for durations of up to 2 years, and less than a year for longer durations).

At the end of the working career, the above-described algorithm was repeated until either the parent retired, or the retirement age was reached. The retirement ages were 55 for males and 54 for females, for workers with unfinished elementary education, and were appropriately modified for workers with higher level of education, emulating statistics on retirement.

\footnotetext{
${ }^{10}$ Wages normalized and the average wageis keept constant.
} 
Figures A1-A5 show key labor market outcomes for the two simulation cohorts. As shown in Figure A1, activity rates steeply increase for the successive age categories, reaching 100 percent in the prime age (25-49), for both generous and modest simulation cohorts. Although in both samples women constitute 81 percent of total population, the percent of active women is much lower both at the beginning and particularly at the end of the working career, the latter reflecting lower mandatory retirement age of women. Moreover, Figure A1 shows that less educated workers enter activity status earlier than more educated -- and, again reflecting retirement rules which are based on the period of services, also leave labor force earlier.

For both men and women, Figure A2 shows an age-earnings profile that monotonically increases with age, and does so particularly steeply for ages 55-59 and 69-64, but only for workers with university level of education (for the generous simulation cohort also for workers with high school). Such profiles are consistent with earnings functions estimates obtained by Orazem and Vodopivec (1997) and Vodopivec (2004). These estimates show that throughout the 1990s, in Slovenia experience commanded a premium which increased nearly linearly with years of service (and therefore age), in line with the regulations of collective agreements, which mandate an automatic wage increase with an increase of work experience. The steep increase for ages 55-59 and 69-64 is produced by selectivity, with workers with lower educational achievement dropping from labor market earlier (see the discussion above).

Figures A3-A4 show the unemployment rate, and the number and duration of unemployment spells, for both generous and modest simulation cohorts. As shown in Figure A3, unemployment rates are of the typical U-shape form, but they decrease strongly for the 60-64 olds, reflecting both selection retirement rules (mostly workers with high educational attainment remain active after 60, and they are much less likely to experience unemployment). Throughout the work life, unemployment rates are lower for more educated workers. Quite expectedly, the number of unemployment spells (during the lifetime) per worker is higher under the modest benefit regime, but the spells are shorter (Figure A4). 
Figure A1: Activity rates and distribution by gender and education, by age, generous and modest simulation cohort
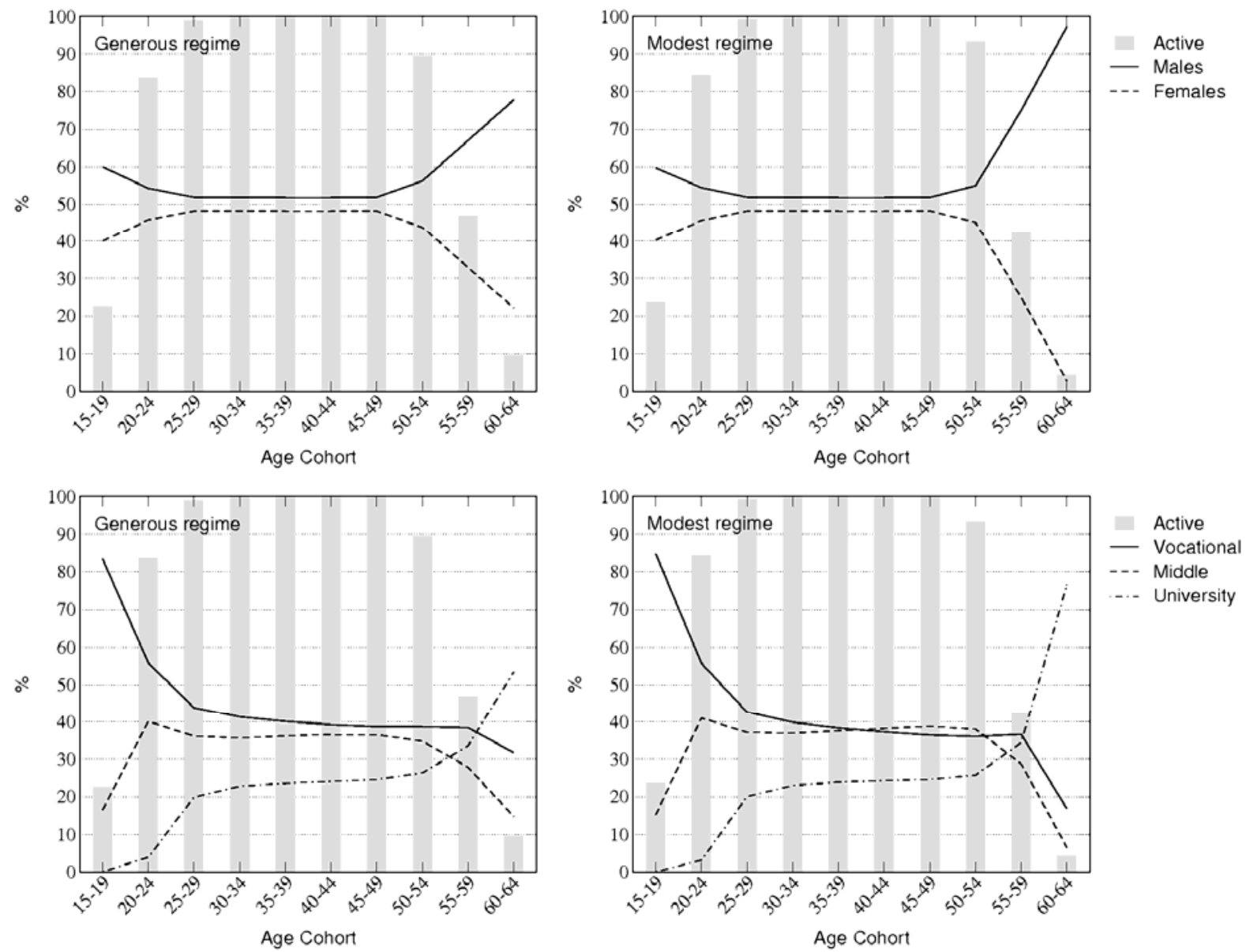
Figure A2: Average wages by age, generous and modest simulation cohort
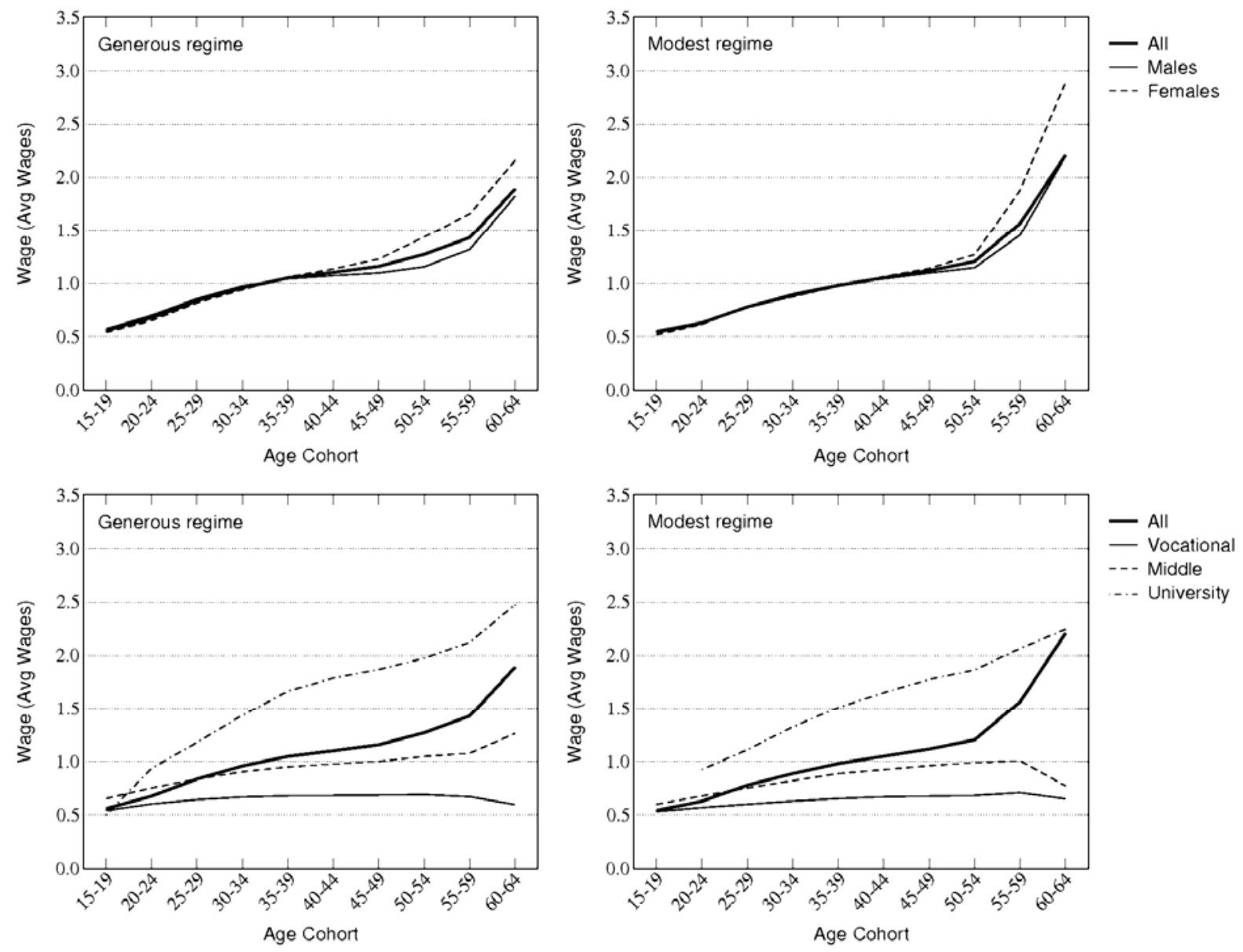
Figure A3: Unemployment rate, generous and modest simulation cohort
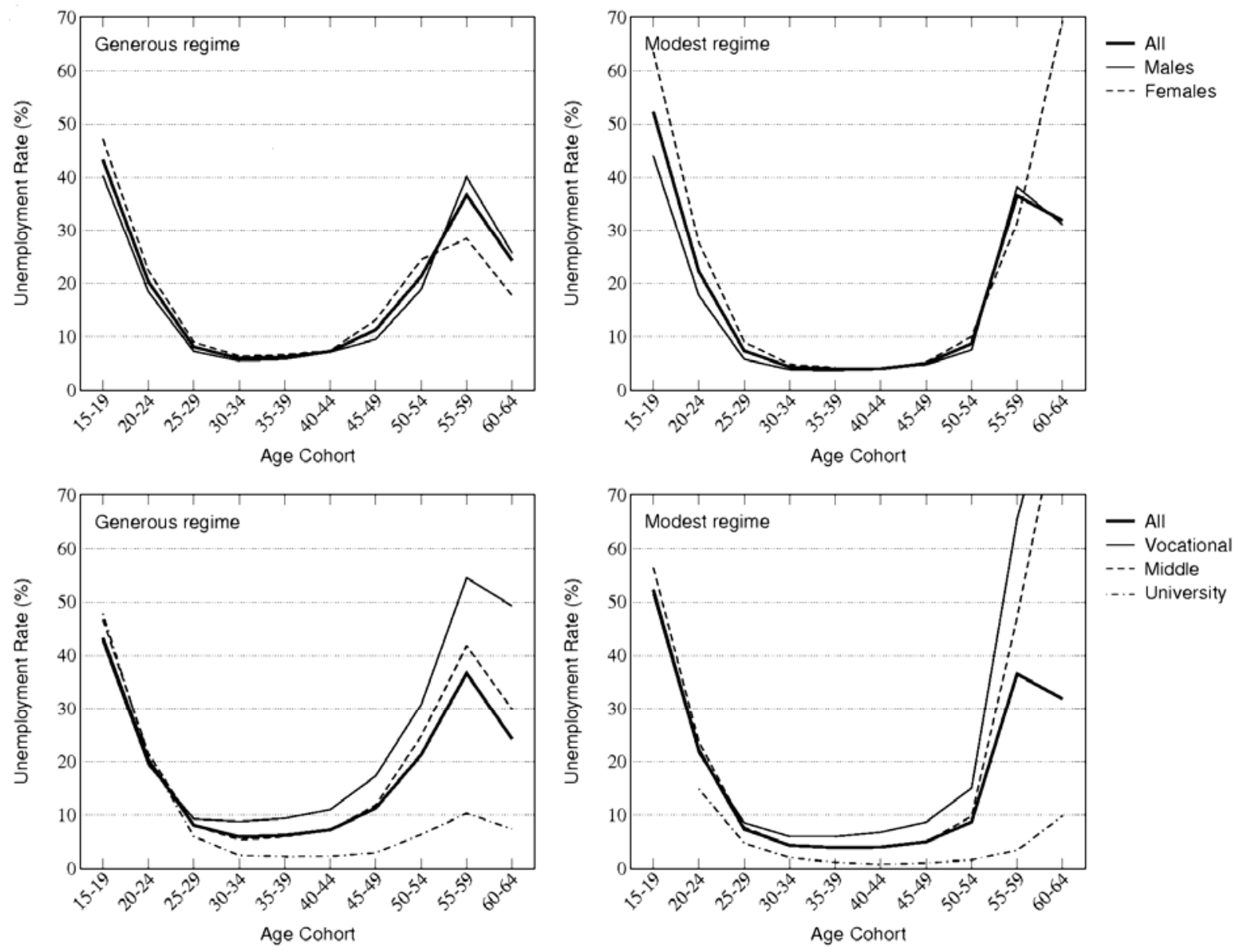
Figure A4: Length distribution of unemployment spells and distribution of the number of unemployment spells, generous and modest simulation cohort
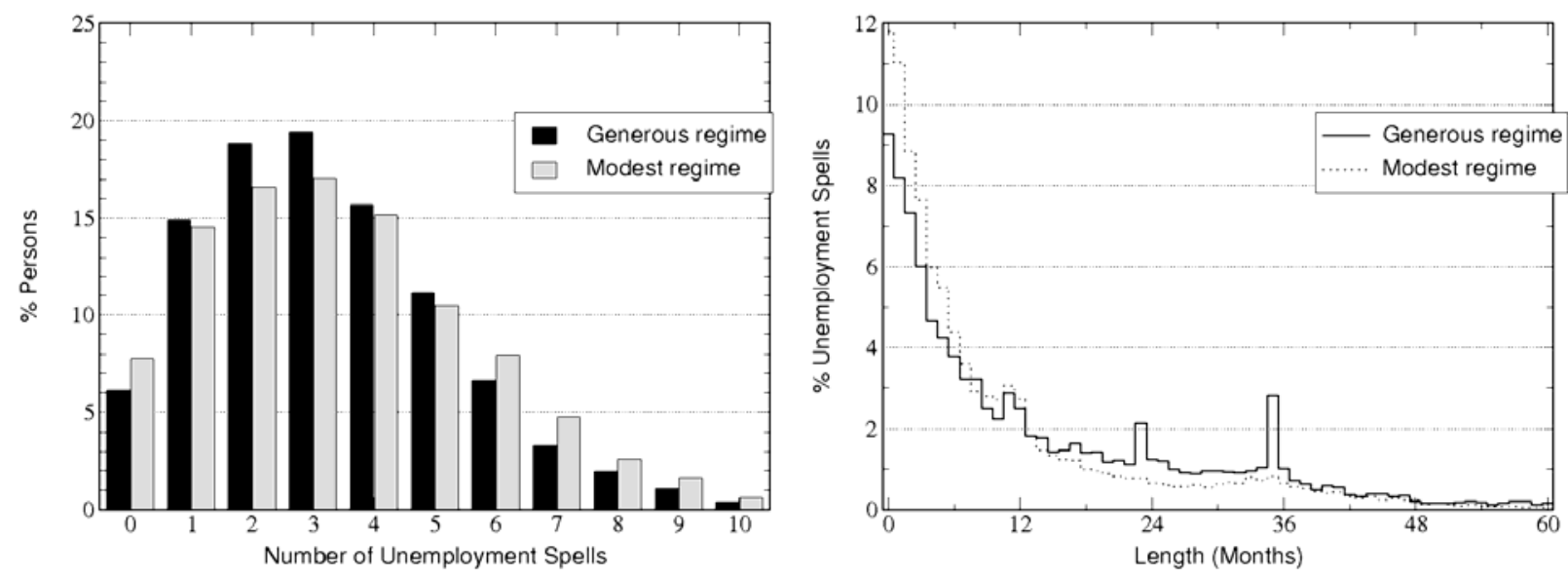

Figure A5: Percentage of unemployed receiving benefits, generous and modest simulation cohort
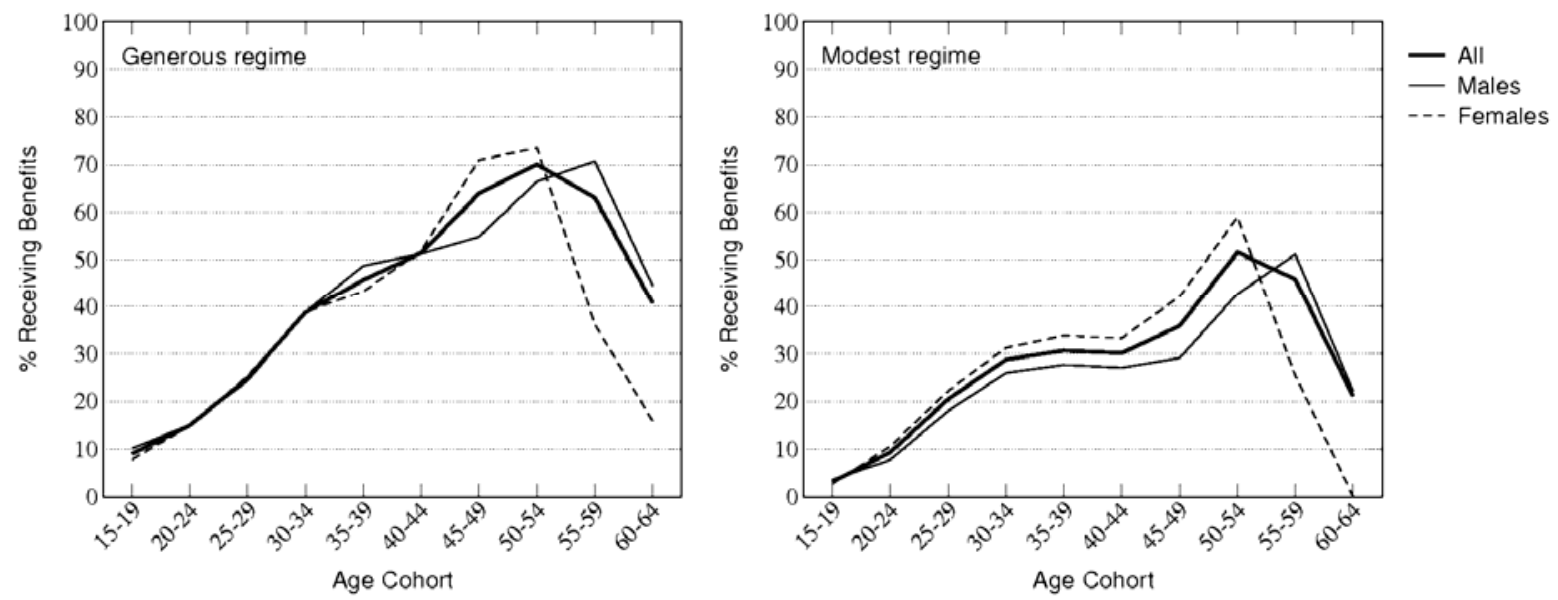


\section{Appendix 2: Calculation of Simulated Variables}

The sum of lifetime wages of the person $p$ earned since the month of his entering into the labor force ( $m_{\text {ENTER }}$ ) till the month of his exit from the labor force $\left(m_{L E A V E}\right)$ is defined as

$$
\text { lifetime _ } \operatorname{wages}(p)=\sum_{m_{\text {ENTER }}}^{m_{\text {LEAVE }}} \operatorname{wages}(p, m) \times r^{m_{L E A V E}-m} \text {. }
$$

Here wages $(p, m)$ is either the wage person earns in month $m$ or zero if he is not employed in that month, and $r$ is the monthly interest rate. Averaging over population of $N_{p}$ persons, the average sum of wages is obtained as

$$
\overline{\text { lifetime_wages }}=\frac{1}{N_{p}} \sum_{p} \text { lifetime_ } \operatorname{wages}(p) .
$$

Quintiles of persons $Q_{i}$ are defined as groups containing one fifth of total population each such that in the first quintile $\left(Q_{1}\right)$ the persons with the lowest lifetime wages are included, in the second quintile the persons with next higher lifetime wages, etc. Average lifetime wages in a quintile is

$$
\overline{\text { lifetime_wages }}_{i}=\frac{1}{N_{p} / 5} \sum_{p \in Q_{i}} \text { liifetime_wages }(p) \text {. }
$$

Lifetime unemployment benefits a person receives, being equal in UI and UISA systems, is

$$
\text { lifetime_unemployment_benefits }(p)=\sum_{m_{\text {ENTER }}}^{m_{L E A V E}} \text { unemployment_benefits }(p, m) \times r^{m_{\text {LEAVE }}-m} \text {, }
$$

This sum can be split into a part received during the grace period of $n_{\text {GRACE }}$ months,

$$
\text { grace_unemployment_benefits }(p)=\sum_{m_{\text {ENTER }}}^{m_{\text {ENTER }}+n_{\text {GRACE }}-1} \text { unemployment_benefits }(p, m) \times r^{m_{L E A V E}-m} \text {, }
$$

and a part received after the grace period - let us name it regular_unemployment_benefits $(p)$.

Lifetime contributions of a person to his/her UISA is

$$
\text { lifetime_contributions }(p)=\sum_{m_{\text {ENTER }}}^{m_{\text {LAVE }}} \text { contributions }(p, m) \times r^{m_{L E A V E}-m} .
$$

The terminal balance in the UISA on the month of leaving labor force is

terminal_balance $(p)=$ total_contributions $(p)$-regular_unemployment_benefits $(p)$, and could be either positive or negative. If it is positive, person is paid the corresponding amount at retirement,

$$
\text { terminal_payment }(p)=\max (0, \text { terminal_balance }(p)) \text {. }
$$

For the quantities introduced above, averages over population and quintiles are defined in the same way as for wages.

The taxation rate needed to cover unemployment benefits under the UI system is defined as:

$$
\text { taxation_rate }_{U I}=\overline{\text { lifetime_unemployment_benefits }} / \overline{\text { lifetime_wages }} \text {. }
$$


Under the UISA system, wages are also taxed to cover the part of unemployment benefits of the persons with negative terminal account balances which is not covered by individuals themselves, and to finance unemployment benefits during the grace period. The benefits of the person financed by taxes are thus:

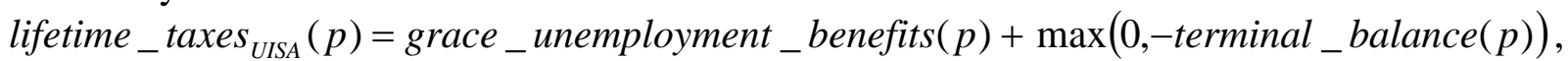
The taxation rate under UISA system is thus

$$
\text { taxation_rate }_{\text {UISA }}=\overline{\text { lifetime_taxes }}_{\text {UISA }} / \overline{\text { lifetime_wages }} \text {. }
$$

Finally, the quantities appearing in the redistribution calculations are defined as follows. Under the UI system, the person's net benefit is

$$
\begin{aligned}
\text { net_benefit }_{U I}(p)= & + \text { lifetime_unemployment_benefits }(p) \\
& \text { - lifetime_wages }(p) \times \text { taxation_rate }_{U I},
\end{aligned}
$$

while in the UISA system it is

$$
\begin{aligned}
& \text { net_benefit }{ }_{\text {UISA }}(p)=+ \text { lifetime_unemployment_benefits }(p) \\
& + \text { terminal_payment }(p) \\
& \text { - lifetime_contributions }(p) \\
& \text { - lifetimee _wages }(p) \times \text { taxation _ rate }_{\text {UISA }}
\end{aligned}
$$

In the redistribution tables the quintile averages of the quantities appearing in the above formulae are presented. 